\title{
Comparison of XCO abundances from the Total Carbon Column Observing Network and the Network for the Detection of Atmospheric Composition Change measured in Karlsruhe
}

\author{
Matthäus Kiel $^{1}$, Frank Hase ${ }^{1}$, Thomas Blumenstock ${ }^{1}$, and Oliver Kirner ${ }^{2}$ \\ ${ }^{1}$ Institute of Meteorology and Climate Research, Karlsruhe Institute of Technology, Karlsruhe, Germany \\ ${ }^{2}$ Steinbuch Centre for Computing (SCC), Karlsruhe Institute of Technology, Karlsruhe, Germany
}

Correspondence to: Matthäus Kiel (matthaeus.kiel@kit.edu)

Received: 23 November 2015 - Published in Atmos. Meas. Tech. Discuss.: 18 January 2016

Revised: 31 March 2016 - Accepted: 16 April 2016 - Published: 20 May 2016

\begin{abstract}
We present a comparison of Karlsruhe XCO records (April 2010-December 2014) from the Total Carbon Column Observing Network (TCCON) and from the spectral region covered by the Network for the Detection of Atmospheric Composition Change (NDACC). The Karlsruhe TCCON Fourier transform infrared (FTIR) spectrometer allows us to record spectra in the mid-infrared (MIR) and nearinfrared (NIR) spectral region simultaneously, which makes Karlsruhe a favourable FTIR site to directly compare measurements from both spectral regions. We compare $\mathrm{XCO}$ retrieved from the fundamental absorption band at $4.7 \mu \mathrm{m}$ (as used by NDACC) and first overtone absorption band at $2.3 \mu \mathrm{m}$ (TCCON-style measurements). We observe a bias of $(4.47 \pm 0.17)$ ppb between both data sets with a standard deviation of $2.39 \mathrm{ppb}$ in seasonal variation. This corresponds to a relative bias of $(4.76 \pm 0.18) \%$ and a standard deviation of $2.28 \%$. We identify different sources which contribute to the observed bias (air-mass-independent correction factor, airmass-dependent correction factor, isotopic identities, differing a priori volume mixing ratio profiles) and quantify their contributions. We show that the seasonality in the residual of NDACC and TCCON XCO can be largely explained by the smoothing effect caused by differing averaging kernel sensitivities between the MIR and NIR spectral region. This study aims to improve the comparability of NDACC and TCCON $\mathrm{XCO}$ validation data sets as desired for potential future satellite missions and model studies.
\end{abstract}

\section{Introduction}

Carbon monoxide $(\mathrm{CO})$ is an atmospheric trace gas which is of utmost importance for air quality studies. Natural sources of $\mathrm{CO}$ in the troposphere are soils, plants, oceans, natural bush, and forest fires. In the stratosphere, the oxidation of methane $\left(\mathrm{CH}_{4}\right)$ and other non-methane hydrocarbons (NMHC) is the key driver in the production of atmospheric CO (Daniel and Solomon, 1998). The main anthropogenic sources of emitted $\mathrm{CO}$ into the atmosphere are incomplete combustion of fossil fuels, biomass burning, and other industrial processes. The significance of $\mathrm{CO}$ for the formation of ozone $\left(\mathrm{O}_{3}\right)$ directly influences the air quality in the troposphere and stratosphere (Seiler and Fishman, 1981). The primary sink of $\mathrm{CO}$ is the oxidation with the hydroxyl radical $\mathrm{OH}$ (Spivakovsky et al., 2000). Therefore, elevated global concentrations of CO implicitly affect global warming (Daniel and Solomon, 1998) and are of interest in today's environmental sciences.

Global measurements from space-based instruments provide valuable data records of $\mathrm{CO}$ concentrations and distributions in the Earth's atmosphere. In recent years, several satellite missions were launched and provided long-term observations of atmospheric CO (e.g. Buchwitz et al., 2007; Deeter et al., 2003; Clerbaux et al., 2008). These measurements are confirmed and validated by ground-based data records which provide similar quantities as measured by satelliteborne instruments (de Laat et al., 2010). Nevertheless, validations and comparisons of retrieval results from different remote sounders are not straightforward and still require ad- 
ditional mathematical methods as well as significant interpretive work (Rodgers and Connor, 2003).

Currently, two global ground-based networks operating Fourier transform infrared (FTIR) spectrometers, namely the Total Carbon Column Observing Network (TCCON, Wunch et al., 2011) and the Network for the Detection of Atmospheric Composition Change (NDACC, Kurylo, 1991), provide primary validation data records of various atmospheric components including CO.

The TCCON approximates column-averaged abundances of several atmospheric gases which are subject to the usual restrictions of the remote-sensing technique, e.g. non-perfect averaging kernels and a priori knowledge. Currently, 23 globally distributed TCCON instruments measure column abundances from solar absorption spectra in the near-infrared (NIR) spectral region. The TCCON retrieval results are tied to the World Meteorological Organization (WMO) scale via aircraft and AirCore profiles to account for systematic biases that are consistent throughout the network (Washenfelder et al., 2006; Deutscher et al., 2010; Wunch et al., 2010; Messerschmidt et al., 2011; Geibel et al., 2012; Karion et al., 2010). Furthermore, the TCCON guidelines imply that instruments and retrieval strategies (including spectroscopic line lists, line shapes, etc.) are as similar as possible at each site. This improves the site-to-site precision and accuracy. TCCON CO retrievals are done from the $2.3 \mu \mathrm{m}$ overtone absorption band, the same band which is used for retrievals of data sets measured by e.g. the Scanning Imaging Absorption Spectrometer for Atmospheric Cartography (SCIAMACHY, Bovensmann et al., 1999).

The NDACC first started measuring in 1991 and is composed of more than 70 remote-sensing research stations. The network aims to observe and understand the chemical and physical conditions of the upper troposphere and stratosphere. Within the NDACC, the Infrared Working Group (IRWG) consists of 22 sites spread worldwide that measure absorption spectra in the mid-infrared (MIR) using direct sunlight. Measurements are performed in spectral regions as low as $720 \mathrm{~cm}^{-1}$ and up to $4400 \mathrm{~cm}^{-1}$. NDACC CO retrievals are done from the fundamental absorption band in the MIR at $4.7 \mu \mathrm{m}$. NDACC-IRWG data have been widely used for satellite validations and model studies (e.g. de Laat et al., 2010; Sussmann et al., 2005).

Recently, Borsdorff et al. (2016) identified a global bias of $4 \mathrm{ppb}$ between NDACC and TCCON column-averaged dry-air mole fractions of $\mathrm{CO}(\mathrm{XCO})$ retrievals when validating the SCIAMACHY XCO data product against both ground-based networks. This discrepancy is confirmed by direct comparison of XCO records at sites where both NDACC and TCCON data sets are generated. Data from the Karlsruhe TCCON site provide a direct comparison of NDACC and TCCON data sets since the spectrometer is an extension over the standard TCCON set-up as a dichroic optic allows us to record solar spectra in the MIR and NIR spectral domain simultaneously. Narrow filter bands in the MIR are de- fined by optical filters as recommended by NDACC. Thus the Karlsruhe instrument makes observations in the MIR region which are routinely done by NDACC stations, including measurements of $\mathrm{CO}$ in the fundamental absorption band. Therefore, the Karlsruhe instrument merges an NDACC and TCCON spectrometer in one device.

The identification and quantification of differences between the NDACC and TCCON CO records (e.g. bias, seasonality) is of interest for the validation of future satellite missions like the Sentinel 5 Precursor to be launched in 2016 (Vidot et al., 2012). Furthermore, if an intercalibration procedure between NDACC and TCCON long-term CO time series can be established, a combined ground-based data record of both networks can improve the spatial and temporal coverage of CO data, which is desirable for model studies and validations.

In this paper, we describe the particular Karlsruhe FTIR set-up (Sect. 2) and present the different retrieval strategies for spectra recorded in the MIR and NIR (Sect. 3). We identify differences in the intercomparison of XCO from both networks and quantify their origins, which improves the comparability of XCO data records from both networks (Sect. 4). Finally, we summarize and conclude our findings in Sect. 5.

\section{Karlsruhe FTIR instrumentation}

The Karlsruhe FTIR instrument is located at the Karlsruhe Institute of Technology (KIT), Campus North $\left(49.1^{\circ} \mathrm{N}\right.$, $8.4^{\circ} \mathrm{E}, 110 \mathrm{~m}$ a.s.l.). Karlsruhe experiences a mild climate similar to most cities in the mid-western part of Europe. The flat terrain is a favourable scene for model studies and nadirlooking satellite overpasses. Since 2009, the FTIR spectrometer has been part of the TCCON. The TCCON retrieves total columns of $\mathrm{CO}_{2}, \mathrm{CH}_{4}, \mathrm{CO}, \mathrm{N}_{2} \mathrm{O}, \mathrm{H}_{2} \mathrm{O}, \mathrm{HF}$, and other atmospheric gases from solar spectra in the NIR. These spectra are recorded using a Bruker IFS $125 \mathrm{HR}$ spectrometer (Bruker Optics GmbH, Germany). The Karlsruhe FTIR instrumental set-up is an extension of the standard TCCON set-up (Washenfelder et al., 2006; Wunch et al., 2011) as a dichroic optic (cut-on at $5250 \mathrm{~cm}^{-1}$ ) allows measurements of solar spectra in the MIR and NIR spectral domains simultaneously. The dichroic reflects the MIR spectral domain and transmits the NIR spectral range such that measurements for TCCON and NDACC can be performed simultaneously. Spectral coverage from 1900 to $11000 \mathrm{~cm}^{-1}$ is achieved by simultaneous operation of an indium gallium arsenide (InGaAs: from 5250 to $11000 \mathrm{~cm}^{-1}$ ) and indium antimonide (InSb: from 1900 to $5250 \mathrm{~cm}^{-1}$ ) detector.

Whereas the Karlsruhe device differs from the standard TCCON set-up, it is typical from the NDACC perspective. Narrow filter bands are defined by optical filters mounted in front of the InSb diode. Operation of that diode enables the measurement of gases which are routinely measured by 
NDACC stations in the MIR, e.g. $\mathrm{NO}, \mathrm{HCl}, \mathrm{HCN}, \mathrm{C}_{2} \mathrm{H}_{2}$, $\mathrm{C}_{2} \mathrm{H}_{4}, \mathrm{NO}_{2}$, and $\mathrm{C}_{2} \mathrm{H}_{6}$. Additionally the fundamental absorption band of $\mathrm{CO}$ lies in the covered spectral range. Although the Karlsruhe instrument conforms to almost all the NDACC criteria, it does not cover the full spectral range as recommended by NDACC (as low as $720 \mathrm{~cm}^{-1}$ ) due to the lack of a mercury cadmium telluride (MCT) detector. Therefore, retrievals of e.g. ozone $\left(\mathrm{O}_{3}\right)$ at $1000 \mathrm{~cm}^{-1}$ are not performed in Karlsruhe.

Due to the simultaneous recording in the MIR and NIR, the total column of $\mathrm{O}_{2}$ retrieved from the $7885 \mathrm{~cm}^{-1}$ absorption band in the NIR can be used to calculate columnaveraged dry-air mole fractions (DMFs) for gases retrieved from MIR spectra. This is superior to standard NDACC instruments, which in general do not have access to the oxygen absorption band located in the NIR. Dividing the total column of the gas of interest by the total column of $\mathrm{O}_{2}$ minimizes measurement and instrumental errors which are common to both gases (e.g. solar tracker mis-pointing, instrumental line shape errors, zero-level offsets) and improves the precision of the measurement (Washenfelder et al., 2006; Wunch et al., 2011).

For TCCON-style CO measurements the instrument is operated at a maximum optical path difference $\left(\mathrm{OPD}_{\max }\right)$ of $45 \mathrm{~cm}$, leading to a spectral resolution of $0.02 \mathrm{~cm}^{-1}$, while NDACC-style $\mathrm{CO}$ measurements are recorded at an $\mathrm{OPD}_{\max }$ of $180 \mathrm{~cm}$.

\section{Retrieval strategies}

Karlsruhe retrievals in the NIR are performed by an adjusted TCCON retrieval strategy which compensates for spectral baseline modulations introduced by the dichroic optic (Kiel et al., 2016). MIR retrievals are performed following the NDACC-IRWG retrieval parameter guidelines. The NDACC retrieval methodology relies on narrow spectral windows, typically up to several wave numbers wide. TCCON instead prefers wider spectral windows which might include an entire molecular absorption band of the gas of interest. Using whole absorption bands of molecules minimizes temperature sensitivities and this methodology reduces noise errors of retrieved total columns. In the next sections, we present the retrieval strategies for CO in the MIR and NIR and we study the impact of different a priori information and spectroscopic parameters on retrieved column abundances.

\subsection{NDACC retrieval strategy for CO}

For the analysis of spectra recorded in the MIR, we use the retrieval algorithm PROFFIT (Hase et al., 2004), which is widely used within NDACC and for analyses of lowresolution spectra as recorded with EM27/SUN spectrometers (Bruker Optics GmbH, Germany; Gisi et al., 2012; Hase et al., 2015; Frey et al., 2015; Klappenbach et al.,

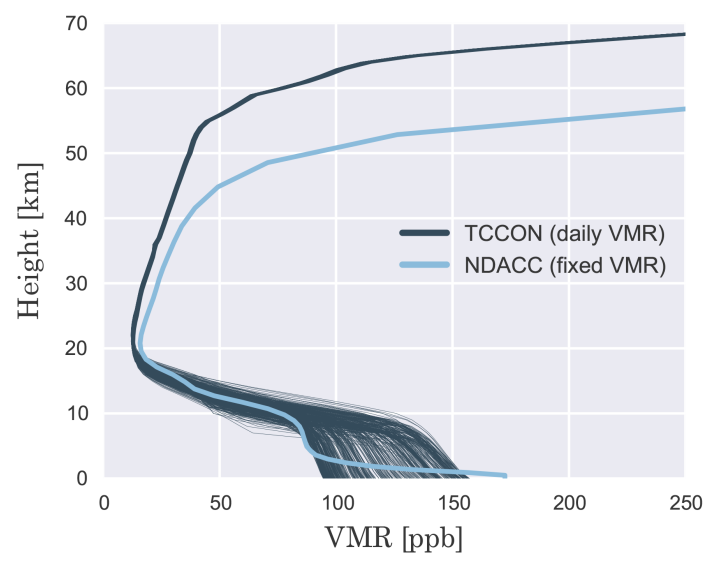

Figure 1. A priori VMR profiles used for the TCCON retrieval of NIR spectra (daily varying profile) and for the NDACC retrieval of MIR spectra (one fixed profile).

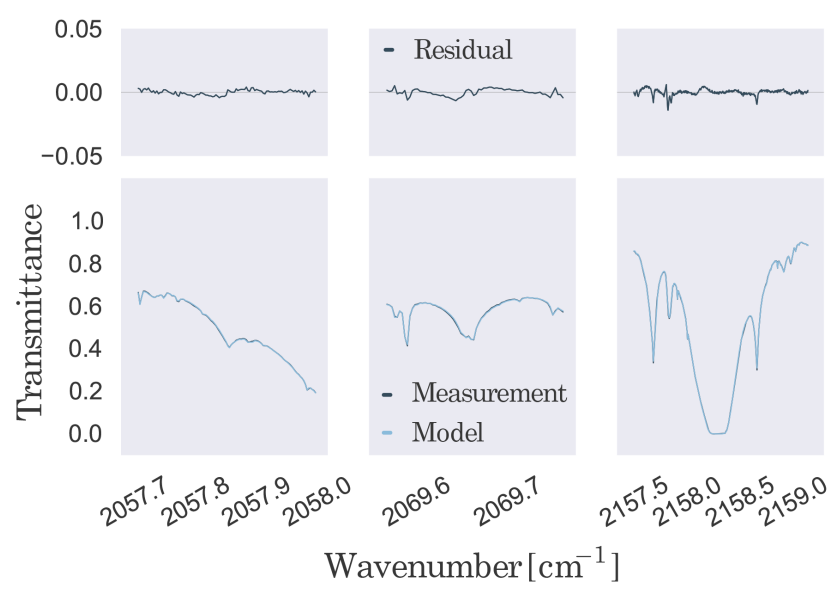

Figure 2. Spectral fits and residuals for CO for one particular Karlsruhe spectrum recorded in the MIR for the three narrow band spectral windows.

2015). PROFFIT is a nonlinear least-squares fitting algorithm which analyses solar absorption spectra on the basis of inversion methods. The algorithm can handle several spectral windows and target gases simultaneously. In addition to the scaling of a priori volume mixing ratio (VMR) profiles (scaling retrieval), PROFFIT is also able to retrieve the vertical gas profile (profile retrieval). The latter is used in this study to retrieve total columns of CO from MIR spectra. PROFFIT is utilized for a full profile retrieval using an inverse covariance. To retrieve total columns of $\mathrm{CO}$ from MIR spectra, we use three narrow spectral windows in the CO fundamental absorption band ranging from 2057.5 to $2058.2 \mathrm{~cm}^{-1}$, from 2069.4 to $2069.9 \mathrm{~cm}^{-1}$, and from 2140.4 to $2141.4 \mathrm{~cm}^{-1}$ (Kramer, 2007). We apply a constrained profile retrieval similar to the retrieval strategy described by Sussmann et al. (2011) for $\mathrm{CH}_{4}$. We use a firstorder Tikonhov-Phillips regularization $\left(L_{1}\right)$ on a logarithmic 
Table 1. Retrieval strategies for CO for spectra recorded in the MIR and NIR spectral region.

\begin{tabular}{lll}
\hline & NDACC retrieval & TCCON retrieval \\
\hline spectral windows $\left[\mathrm{cm}^{-1}\right]$ & $2057.5-2058.2$ & $4208.7-4257.3$ \\
& $2069.4-2069.9$ & $4262.0-4318.8$ \\
& $2157.5-2159.2$ & \\
interfering gases & $\mathrm{CO}_{2}, \mathrm{OCS}, \mathrm{O}_{3}, \mathrm{~N}_{2} \mathrm{O}, \mathrm{H}_{2} \mathrm{O}$ & $\mathrm{CH}_{4}, \mathrm{H}_{2} \mathrm{O}, \mathrm{HDO}$ \\
retrieval algorithm & PROFFIT V9.6 & $\mathrm{GGG}^{2014}$ (GFIT) \\
line list & HITRAN 2008, & based on \\
& HITRAN 2009 $\left(\mathrm{H}_{2} \mathrm{O}, \mathrm{HDO}\right)$ & HITRAN 2012 \\
retrieval constraint & Tikhonov-Phillips & scaling of a priori VMR profile \\
& $L_{1}$ regularization & \\
& (DOF* $\approx$ 3.0) & \\
a priori VMR profile & WACCM V.6 (fixed) & based on in situ \\
& & measurements (daily) \\
\hline
\end{tabular}

$*$ degrees of freedom (DOF)

scale (Hase et al., 2004; Schneider et al., 2006). The signalto-noise ratio is empirically obtained from the fit residual and the regularization strength is tuned such that approximately 3 degrees of freedom are reached. The a priori VMR profile is obtained from the Whole Atmospheric Chemistry Climate Model (WACCM; Garcia et al., 2007) as recommended by NDACC. We use one fixed a priori VMR profile for the entire temporal range of our study (April 2010-December 2014) which represents the average obtained from model runs from 1980 to 2020 for Karlsruhe (see Fig. 1). We use the High Resolution Transmission (HITRAN; Rothman et al., 2009) line list from 2008 in its original form for $\mathrm{CO}$ and interfering species (see Table 1) except for $\mathrm{H}_{2} \mathrm{O}$ and HDO. For $\mathrm{H}_{2} \mathrm{O}$ and HDO we use the HITRAN 2009 line list update. Spectral fits and residuals (the difference between the computed and measured spectrum) for $\mathrm{CO}$ for one particular measurement in the MIR are depicted in Fig. 2. We use pressure and temperature profiles allowing for intra-day variability based on eight individual profiles for one measurement day. These profiles are taken from measurements obtained from instruments installed at the Karlsruhe meteorological tall tower (200 m), which is located at KIT near the FTIR observatory, and the Modern-Era Retrospective analysis for Research and Applications (MERRA; Rienecker et al., 2011) model data, which provide temperature and pressure profiles on a $1.25^{\circ} \times 1.25^{\circ}$ grid, from 1000 to $0.1 \mathrm{hPa}$, eight times per day. For each of the eight time points, the solar position is calculated and the pressure and temperature along the unrefracted path of the solar radiation is retrieved from the model data (Gisi et al., 2012).

\subsection{TCCON retrieval strategy for CO}

For TCCON-style measurements in the NIR, the recorded interferograms are analysed with the GGG2014 Software Suite which includes GFIT, a nonlinear least-squares spectral fitting algorithm (Wunch et al., 2015). Total columns of CO
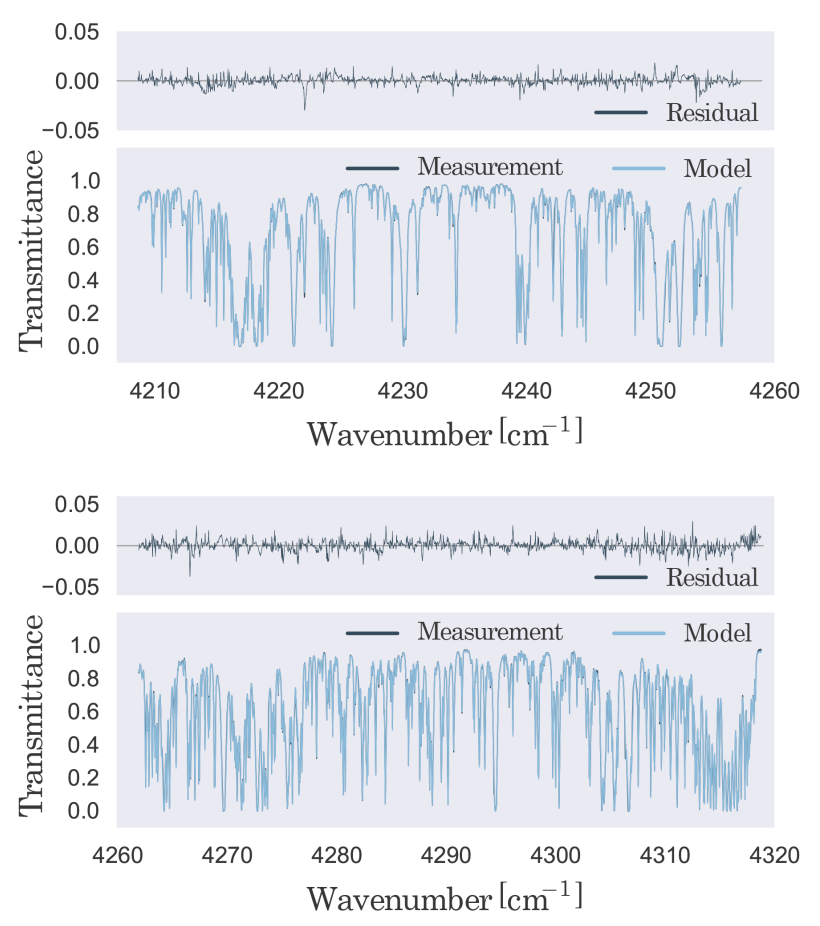

Figure 3. Spectral fits for one particular Karlsruhe spectrum recorded in the NIR; spectral fit and residual for CO in the 4208.7 to $4257.3 \mathrm{~cm}^{-1}$ (upper panel) and 4262.0 to $4328.8 \mathrm{~cm}^{-1}$ (lower panel) spectral window.

are retrieved by scaling an a priori VMR profile. GFIT uses daily a priori VMR profiles which are generated by a set of empirical functions that are optimized to fit in situ measurements (e.g. Toon, 1991; Messerschmidt et al., 2011; Geibel et al., 2012; Karion et al., 2010; Wofsy, 2011). The TCCON a priori VMR profiles used in this study are depicted in Fig. 1. To retrieve total columns of CO from NIR spectra, two broad spectral windows in the $\mathrm{CO}$ overtone absorption 
band ranging from 4208.7 to $4257.3 \mathrm{~cm}^{-1}$ and from 4262.0 to $4318.8 \mathrm{~cm}^{-1}$ are fitted. Interfering species are $\mathrm{CH}_{4}, \mathrm{H}_{2} \mathrm{O}$, and HDO. For TCCON-style CO retrievals, an adopted HITRAN 2012 line list (Rothman et al., 2013) is used. For $\mathrm{H}_{2} \mathrm{O}$, many changes were applied to the original list throughout the 4000 to $6000 \mathrm{~cm}^{-1}$ region based on fits made to Kitt Peak laboratory spectra (Wunch et al., 2015). Spectral fits for CO for one particular measurement in the NIR are depicted in Fig. 3. Ten minute means of the ground pressure and surface temperature obtained from the Karlsruhe tall tower are used as auxiliary data for the Karlsruhe TCCON retrievals. A summary of the CO retrieval strategies for MIR and NIR spectra is given in Table 1.

\subsection{Calculation of DMFs}

To calculate column-averaged DMFs of CO, namely XCO, the total column amount of $\mathrm{CO}\left(\mathrm{C}_{\mathrm{CO}}\right)$ is divided by the total column of dry air $\left(\mathrm{C}_{\text {dryair }}\right)$ :

$\mathrm{XCO}=\frac{\mathrm{C}_{\mathrm{CO}}}{\mathrm{C}_{\mathrm{dryair}}}$.

For TCCON, $\mathrm{C}_{\text {dryair }}$ is determined via the total column of $\mathrm{O}_{2}\left(\mathrm{C}_{\mathrm{O}_{2}}\right)$ retrieved from the $7885 \mathrm{~cm}^{-1}$ absorption band in the NIR divided by an assumed dry-air mole fraction of $\mathrm{O}_{2}$ (0.2095):

$\mathrm{C}_{\text {dryair }}=\frac{\mathrm{C}_{\mathrm{O}_{2}}}{0.2095}$.

In general, standard NDACC instruments which only measure in the MIR do not have access to the $\mathrm{O}_{2}$ absorption band in the NIR. Instead, $\mathrm{C}_{\text {dryair }}$ can be calculated on the basis of the ground pressure $p_{\mathrm{g}}$ and the total column of water vapour $\left(\mathrm{C}_{\mathrm{H}_{2} \mathrm{O}}\right)$ :

$\mathrm{C}_{\text {dryair }}=\frac{p_{\mathrm{g}}}{g \cdot m_{\text {dryair }}}-\frac{\mathrm{C}_{\mathrm{H}_{2} \mathrm{O}} \cdot m_{\mathrm{H}_{2} \mathrm{O}}}{m_{\text {dryair }}}$.

Here, $g$ represents the gravitational acceleration whereas $m_{\text {dryair }}$ and $m_{\mathrm{H}_{2} \mathrm{O}}$ represent the molecular masses of dry air and water vapour respectively.

Since the Karlsruhe FTIR set-up allows us to record spectra in the MIR and NIR simultaneously, we use Eq. (2) to calculate XCO from the fundamental absorption band in the MIR instead of Eq. (3). The advantage of calculating DMFs using Eq. (2) is that solar tracker problems leading to mis-pointing and zero-level offsets can be minimized since both $\mathrm{C}_{\mathrm{CO}}$ and $\mathrm{C}_{\text {dryair }}$ are affected by the particular error in the same way. Therefore, for NDACC FTIR sites it is worth considering extending the accessible spectral range to the $7885 \mathrm{~cm}^{-1} \mathrm{O}_{2}$ absorption band to minimize such errors. For the retrieval of $\mathrm{O}_{2}$, both retrieval algorithms, GFIT and PROFFIT, scale an altitude-independent a priori VMR profile using the spectral window ranging from 7765.0 to $8005.0 \mathrm{~cm}^{-1}$. The corresponding spectral fits retrieved by GFIT and PROFFIT are depicted in Fig. 4.
The $\mathrm{C}_{\mathrm{O}_{2}}$ from the $7885 \mathrm{~cm}^{-1}$ absorption band retrieved with GGG2014 and PROFFIT are in good agreement (see Fig. A1 in Appendix A). We identify a bias of $(0.04 \pm 0.02) \%$ with a standard deviation of $0.09 \%$. Using Eq. (3) to determine $\mathrm{C}_{\text {dryair }}$ for MIR spectra (using PROFFIT for the $\mathrm{H}_{2} \mathrm{O}$ retrieval) indicates a bias of $(-2.28 \pm 0.01) \%$ with a standard deviation of $0.13 \%$ (see Fig. A2 in Appendix A) when compared with $\mathrm{C}_{\text {dryair }}$ obtained from Eq. (2) (using GGG2014). The small standard deviation indicates that the improvement achieved by dividing by $\mathrm{C}_{\mathrm{O}_{2}}$ does not offer a significant improvement for a species of large natural variability observed with state-of-the-art NDACC instrumentations. The bias of $-2.28 \%$ is mainly due to spectroscopic inadequacies attributed to oxygen line intensity errors and is in good agreement with a bias of $-2.27 \%$ observed by Washenfelder et al. (2006). However, despite the constant bias, the advantage of Eq. (2) is that errors in retrieved total columns of $\mathrm{H}_{2} \mathrm{O}$ as well as rare but still possible inadequacies in measurements of the ground pressure due to instrument failure do not contribute to the total dry-air column. Moreover, errors that are common to $\mathrm{CO}$ and $\mathrm{O}_{2}$ are minimized, e.g. mis-pointing of the solar tracker and zero-level offsets, and hence a direct comparison of XCO from the fundamental and the first overtone absorption band is improved.

TCCON measurements are tied to the WMO scale. Calculated DMFs retrieved in the NIR are divided by a correction factor determined via in situ aircraft measurements flown over TCCON sites (Washenfelder et al., 2006; Deutscher et al., 2010; Wunch et al., 2010; Messerschmidt et al., 2011; Geibel et al., 2012). For TCCON XCO the correction factor is 1.0672 . For MIR retrievals, we do not apply a postprocessing correction.

\subsection{Impact of a priori choice}

The choice of a priori information influences the retrieved column abundances and has to be taken into account for an intercomparison of different soundings (Rodgers and Connor, 2003). We follow the MIR and NIR retrieval strategies with (1) the standard a priori VMR profiles and (2) switched a priori profiles for both retrieval strategies. For the analysis we use data from April 2010 to December 2014 and calculate daily means for days with at least two measurements. The seasonal bias induced by the change of the a priori VMR profile for the NDACC XCO retrieval is shown in Fig. 5. We identify a bias of $(-0.20 \pm 0.18)$ ppb in the absolute difference time series and a seasonal cycle with a standard deviation of $0.39 \mathrm{ppb}$.

The absolute difference time series for the XCO TCCON scaling retrieval using different a priori VMR profiles is shown in Fig. 6. The number of daily means is larger in the TCCON time series (487 days) than in the NDACC time series (295 days), because we only take into account days with more than one spectrum per day. Typically, we alternately record spectra by using different narrow band filters mounted 

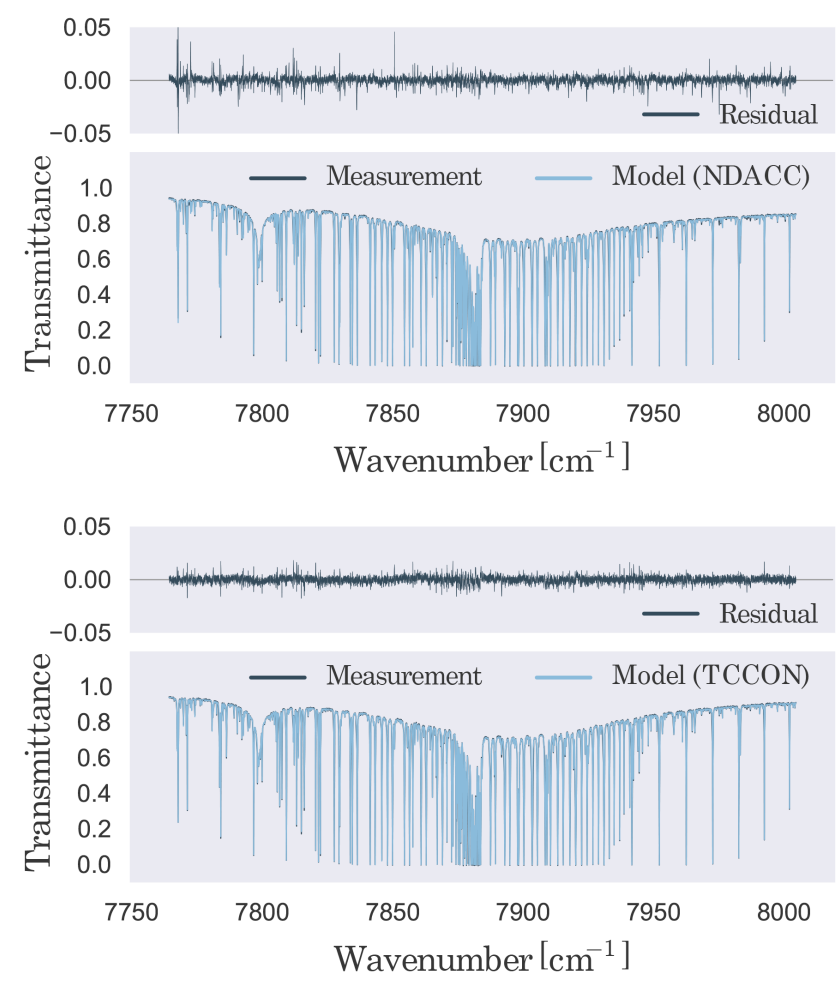

Figure 4. Spectral fits and residuals for one particular Karlsruhe spectrum recorded in the NIR for $\mathrm{O}_{2}$ retrieved with PROFFIT (upper panel) and GGG2014 (lower panel). Residuals in the NIR are smaller due to the adoption of $\mathrm{H}_{2} \mathrm{O}$ absorption line parameters in the line list used for the TCCON retrieval.
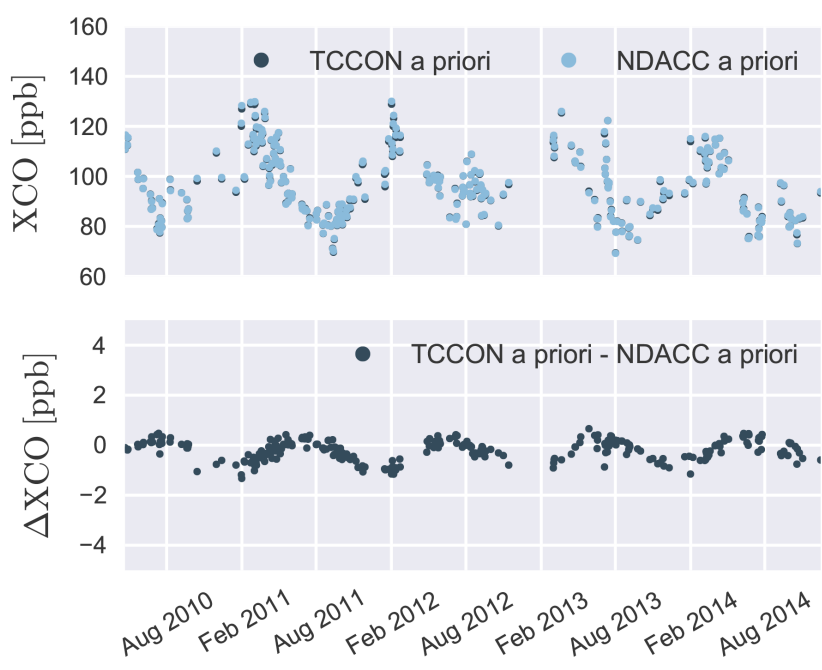

Figure 5. Upper panel: daily mean time series of XCO retrieved from MIR spectra using different a priori VMR profiles; lower panel: the absolute difference time series shows the impact of changing the a priori profiles.

in front of the InSb diode while simultaneously recording NIR spectra with the InGaAs diode. However, the narrow band filters in front of the InSb diode are shuffled in an order
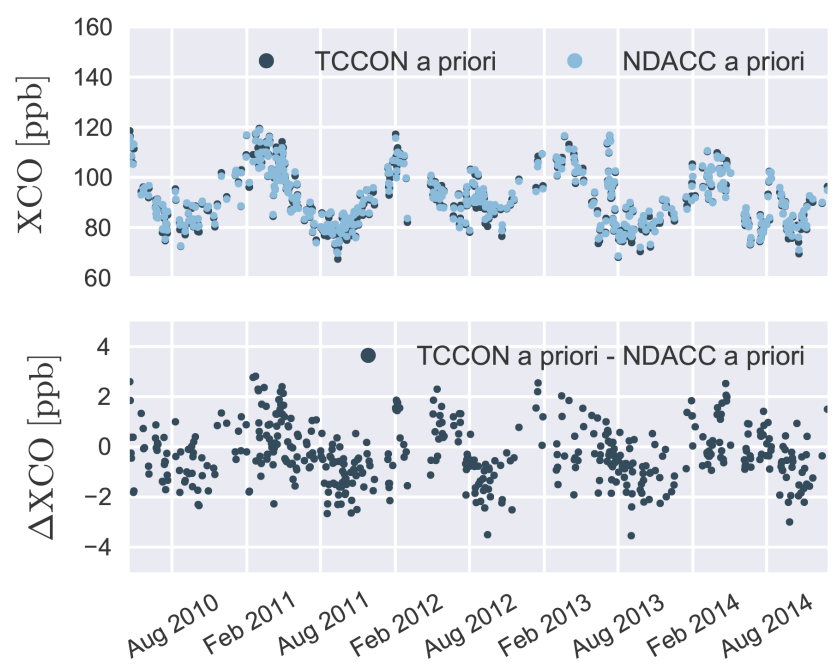

Figure 6. Same as Fig. 5 for XCO retrieved from NIR spectra using the TCCON retrieval strategy with changed a priori VMR profiles.

that every other spectrum covers the $\mathrm{CO}$ first overtone band, leading to a larger number of TCCON-style $\mathrm{CO}$ measurements than NDACC-style measurements covering the fundamental band. For the TCCON XCO time series we identify a significant bias of $(0.30 \pm 0.12)$ ppb with a standard deviation of $1.15 \mathrm{ppb}$ in the seasonal variation. Using one fixed a priori VMR profile is a poor choice for a scaling retrieval since it depends on the shape of the VMR profile which, in general, changes over the year and seasons. Therefore, it is important to use variable daily VMR profiles when performing a scaling retrieval. In general, it is better to use the same a priori VMR profile when comparing two different remote sounders. The retrieved profile $\boldsymbol{x}$ can be expressed as

$\boldsymbol{x}=\mathbf{A}\left(\boldsymbol{x}_{\text {true }}-\boldsymbol{x}_{\text {apriori }}\right)+\boldsymbol{x}_{\text {apriori }}+\boldsymbol{\epsilon}$.

Here, $\boldsymbol{x}_{\text {true }}$ represents the true atmospheric profile, $\boldsymbol{x}_{\text {apriori }}$ the used a priori VMR profile, $\boldsymbol{\epsilon}$ the random and systematic error term, and $\mathbf{A}$ the averaging kernel matrix. Therefore, using a common a priori profile leads to the same value for the difference $\left(\boldsymbol{x}_{\text {true }}-\boldsymbol{x}_{\text {apriori }}\right)$ for both retrieval strategies and eliminates differences in a direct comparison of TCCON and NDACC data due to differing a priori VMR profiles. Nevertheless, the term $\mathbf{A}\left(\boldsymbol{x}_{\text {true }}-\boldsymbol{x}_{\text {apriori }}\right)$ in Eq. (4), here referred to as smoothing effect, still has to be taken into account for an intercomparison. Typically, $\mathbf{A}$ is different for different remote sounders and also influences a direct comparison (see Sect. 4.2).

\subsection{Impact of line list choice}

HITRAN (Rothman et al., 2009, 2013) provides spectroscopic parameters (e.g. line intensities, self-broadening coefficients, air-broadening coefficients, temperature-dependent coefficients) which are used by both retrieval algorithms 

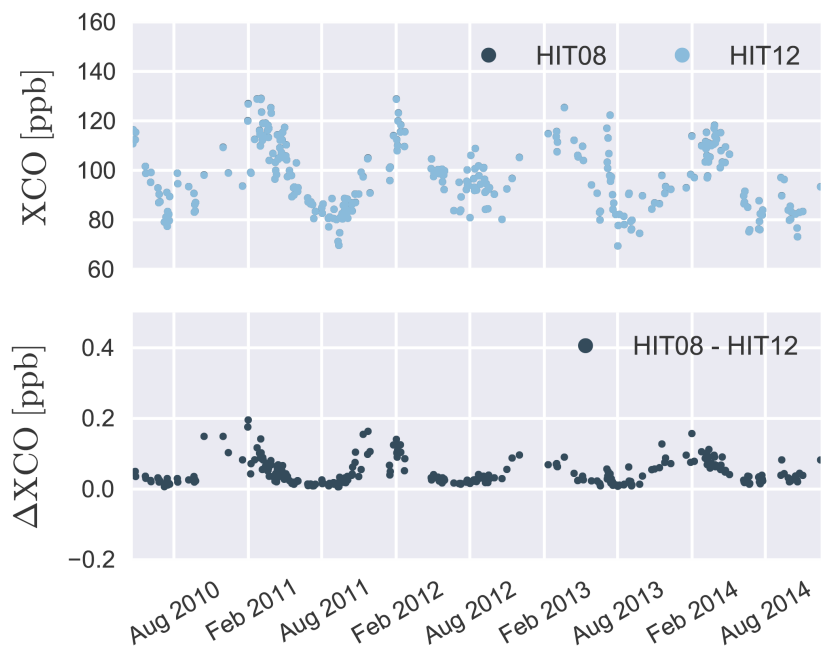

Figure 7. Upper panel: daily mean time series of XCO retrieved from MIR spectra following the NDACC retrieval methodology for the HITRAN 2008 (HIT08) and HITRAN 2012 (HIT12) spectroscopic line lists; lower panel: the absolute difference time series shows the impact from the change of spectroscopic parameters.

(GFIT and PROFFIT) for the forward simulation. For CO retrievals, the TCCON uses spectroscopic parameters based on the HITRAN 2012 line list, whereas the NDACC uses the HITRAN 2008 compilation. We expect that an update from HITRAN 2008 to HITRAN 2012 has minimal impact on the NDACC CO retrieval in the MIR since major changes of the parameters in the 2012 version were primarily applied to the first overtone band in the NIR (Rothman et al., 2013). The NDACC CO time series retrieved with changed HITRAN line lists is depicted in Fig. 7. A bias of $(0.05 \pm 0.17) \mathrm{ppb}$ is induced with a standard deviation of $0.03 \mathrm{ppb}$ in the seasonal variation. The observed peaks in $\triangle \mathrm{XCO}$ during winter are due to line list changes: HITRAN 2012 adds nonzero air-pressure-induced line shifts for the target lines of the NDACC CO retrieval, while the pressure broadening parameters remain unchanged. Due to the fact that an observed spectral line is comprised of absorption contributions from different altitudes, this generates an additional smear of the absorption along the spectral abscissa. As a consequence, in the case of an optically thick line, a smaller number of molecules is required for generating the same attenuation of the solar radiation (spectrally integrated over the whole line) and thereby slightly reduces the retrieved column values.

Accordingly, this effect is revealed by depicting the $\mathrm{CO}$ slant column and its change for different line lists (see Fig. A3 in Appendix A).

Nevertheless, changes in the retrieved CO total columns are rather small using the updated HITRAN 2012 line list. Therefore, the different choice of spectroscopic parameters does not substantially affect the comparison of NDACC and TCCON CO data records.

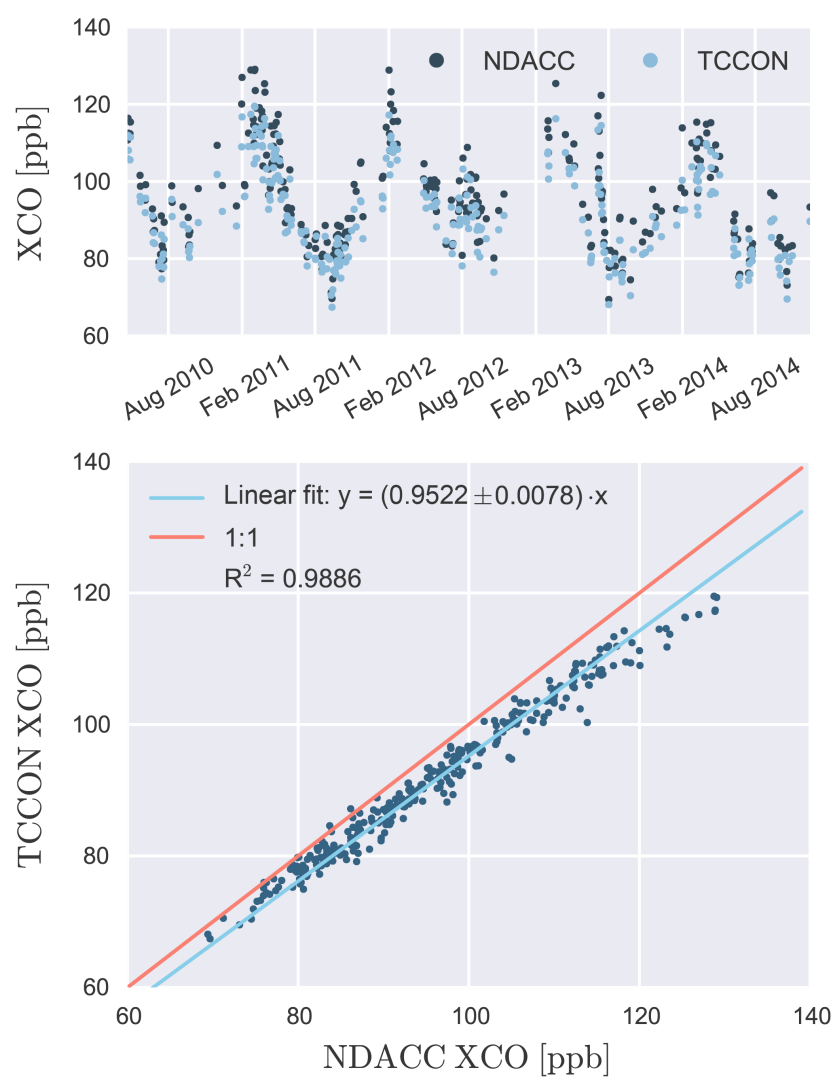

Figure 8. Upper panel: daily mean time series of XCO retrieved from MIR and NIR spectra using the NDACC and TCCON retrieval strategy respectively; lower panel: scatter graph of NDACC and TCCON daily means. The slope was obtained from a linear fit forced through zero.

\section{Direct comparison}

We compare the XCO time series as retrieved (see Fig. 8, upper panel) using the TCCON and NDACC retrieval as described in Table 1. Figure 8 (lower panel) shows a $1: 1$ plot of the NDACC and TCCON daily means from April 2010 to December 2014. The slope obtained from a linear fit forced through zero is significantly different from 1 (0.952244). This corresponds to a bias between both time series. The absolute difference time series (NDACC-TCCON) of the same data is shown in Fig. 9 (upper panel). We identify a bias of $(4.47 \pm 0.17) \mathrm{ppb}$ with a clear difference in seasonality (standard deviation of $2.06 \mathrm{ppb}$ ). In the next sections we analyse the origin of the bias and seasonality when comparing TCCON and NDACC XCO data.

\subsection{Analysis of bias}

We show that the bias is mainly induced by scaling the TCCON data to the WMO scale. As described in Sect. 3.2, TCCON measurements are tied to the WMO scale by dividing DMFs of the target gas by an air-mass-independent 


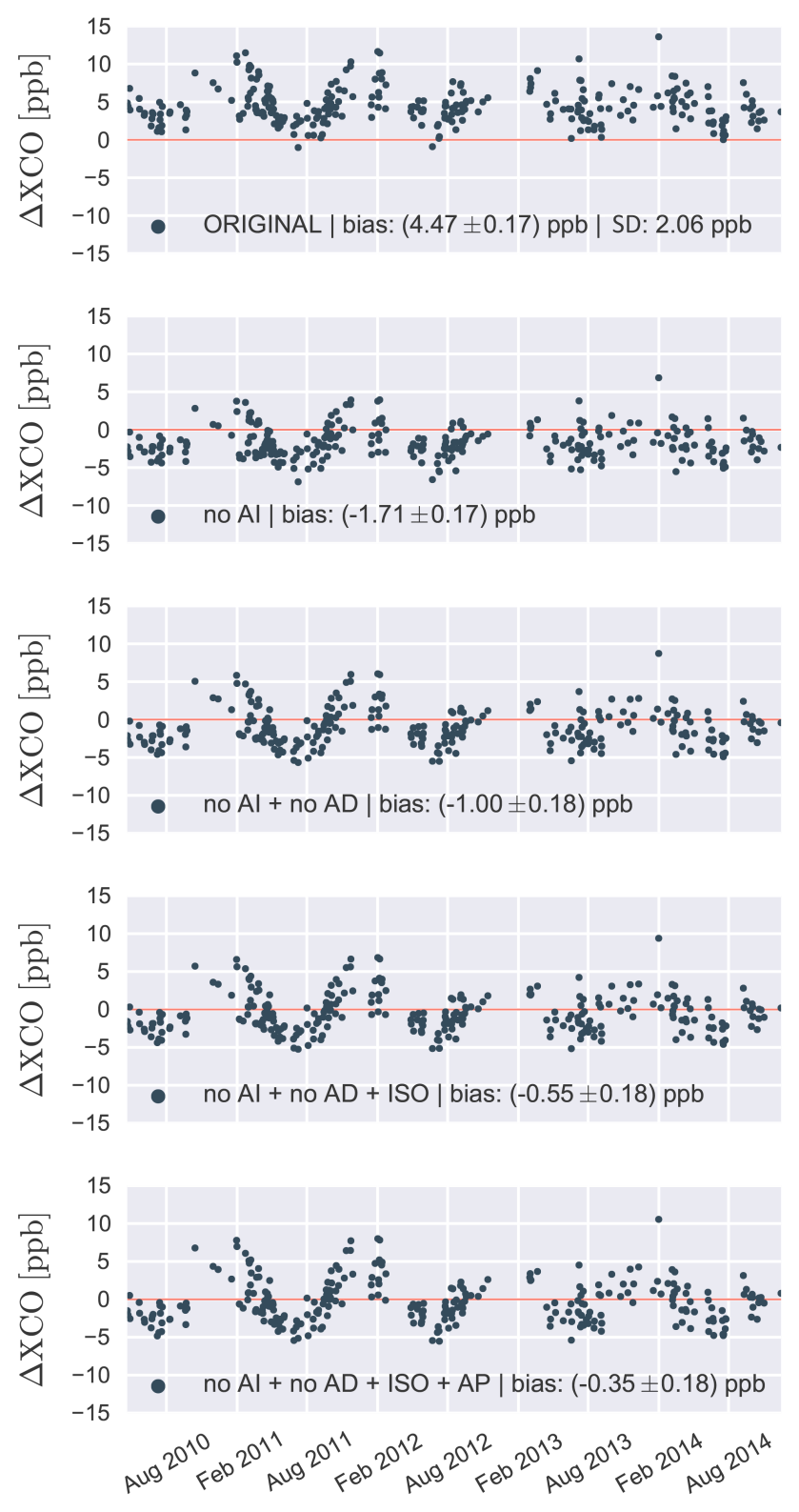

Figure 9. Daily mean absolute difference time series (NDACCTCCON) of XCO for the standard retrievals (first panel, labelled as "ORIGINAL"), no air-mass-independent correction factor (AI) applied (second panel), no air-mass-dependent correction factor (AD) applied (third panel), a modified treatment of isotopic identities applied for the MIR retrieval (ISO, fourth panel), and used common a priori (AP) VMR profiles (fifth panel). Zero lines are marked red and are for eye-guidance only.

correction factor (AI) determined via in situ measurements over TCCON sites. For XCO this correction factor is 1.0672. NDACC measurements are not tied to the WMO scale and no correction factor is applied in the post-processing routine. The absolute difference time series (NDACC-TCCON) without applying AI to TCCON XCO is shown in Fig. 9 (second panel). The mean offset is reduced to $(-1.71 \pm 0.17) \mathrm{ppb}$. Therefore, not applying AI reduces the bias and changes sign. For future studies, it would be favourable to determine an AI for the NDACC XCO data set in the same way as for TCCON. An in situ calibration for NDACC XCO data will most likely improve the consistency between both data sets and will tie the NDACC XCO product to the WMO scale. Since an aircraft overflight can be a very involved and expensive undertaking, a scaling of the NDACC XCO data set to the TCCON XCO data might be an alternative to an aircraft overflight. NDACC XCO can be tied to the WMO scale via an intercalibration factor obtained from the intercomparison of NDACC and TCCON XCO. For Karlsruhe we determine a factor of 1.048 with an corresponding error of 0.002. Therefore, for a joint use of Karlsruhe MIR and NIR XCO, we recommend dividing NDACC XCO by this intercalibration factor. Moreover, a global multi-station intercalibration factor for NDACC and TCCON XCO is desirable and will be subject of future studies.

TCCON data are also corrected for air-mass-dependent artefacts. The air-mass-dependent correction factor (AD) is applied to the column-averaged mole fractions of CO. AD is determined from the symmetric component of the diurnal variation. A detailed description of the method to determine the correction factor and its value is given in Wunch et al. (2011) and Wunch et al. (2015). Here we analyse the impact of applying AD in the post-processing routine of GGG2014 on TCCON measurement. XCO retrieved with and without $\mathrm{AD}$ with respect to the solar zenith angle (SZA) is depicted in Fig. A4 in Appendix A. If AD is applied, XCO is elevated for large SZA and a possible air-mass-dependence is corrected. The change in $\mathrm{XCO}$ due to $\mathrm{AD}$ and the difference between TCCON and NDACC XCO is shown in Fig. A5 in Appendix A. $\triangle \mathrm{XCO}$ between NDACC and TCCON is closer to 0 for large SZA $\left(>50^{\circ}\right)$ when no $\mathrm{AD}$ is applied, whereas applying AD reduces the SZA dependence, which leads to a constant offset between NDACC and TCCON XCO for all SZA. This behaviour is reflected in the difference time series (see Fig. 9, third panel). The bias is further reduced to $(-1.00 \pm 0.17) \mathrm{ppb}$ when we do not apply AD to TCCON $\mathrm{XCO}$ at the expense of an air-mass dependence. For NDACC no clear air-mass dependence is observed and consequently no post-processing air-mass correction is required.

Furthermore, we analyse how isotopic identities of spectral lines lying in the chosen spectral windows influence the observed bias. Basically, line intensities in the HITRAN line list are multiplied by the standard isotopic abundances derived from De Biévre et al. (1984). Hence, both retrieval algorithms return the total VMR of $\mathrm{CO}$, regardless of the isotopic identity of the spectral lines in the used spectral windows. The broad spectral windows used for the TCCON retrieval are dominated by spectral lines from the most abundant $\mathrm{CO}$ isotopologue $\left({ }^{12} \mathrm{C}^{16} \mathrm{O}\right)$, whereas the NDACC retrieval strategy takes into account solar absorption lines from the two most abundant isotopologues ${ }^{12} \mathrm{C}^{16} \mathrm{O}$ (at $2158.3 \mathrm{~cm}^{-1}$ ) and ${ }^{13} \mathrm{C}^{16} \mathrm{O}$ (at 2057.86 and $2069.66 \mathrm{~cm}^{-1}$ ). 
If atmospheric isotopic ratios deviate from the De Biévre et al. (1984) reference values, GGG2014 parameterizes the atmospheric fractionation using improved values. For the two most abundant isotopologues, ${ }^{12} \mathrm{C}^{16} \mathrm{O}$ and ${ }^{13} \mathrm{C}^{16} \mathrm{O}$, GGG2014 uses an altitude-independent $\delta^{13} \mathrm{C}(\mathrm{CO})$ value (the ratio of the isotopologues ${ }^{13} \mathrm{C}^{16} \mathrm{O}$ and ${ }^{12} \mathrm{C}^{16} \mathrm{O}$ ) of $-27 \%$ o (Wang et al., 2012). This parameter corrects for spectroscopic inconsistencies and therefore mainly represents spectroscopic biases between different isotopologues. This is not taken into account in the standard MIR retrieval. Thus, we apply the same isotopic treatment for ${ }^{12} \mathrm{C}^{16} \mathrm{O}$ and ${ }^{13} \mathrm{C}^{16} \mathrm{O}$ as used in the TCCON for the NDACC retrieval. We expect a reduction of the observed bias since two of the spectral windows in the MIR contain ${ }^{13} \mathrm{C}^{16} \mathrm{O}$ absorption lines. The difference time series when the modified treatment of isotopic identities in the MIR is applied is shown in Fig. 9 (fourth panel). We identify a bias of $(-0.55 \pm 0.18) \mathrm{ppb}$. In general, it might be better to use a CO retrieval strategy in the MIR with a modified treatment of different isotopic identities or as an alternative to use narrow spectral windows containing absorption lines without mixed isotopic identities.

In addition, to eliminate the impact of differing a priori VMR profiles, we follow the NDACC retrieval strategy using the TCCON daily a priori VMR profiles. From our findings in Sect. 3.4 we expect a rather small impact of the choice of the a priori VMR profile on the observed bias. The difference time series using common a priori VMR profiles is depicted in Fig. 9 (fifth panel). The bias is further reduced to $(-0.35 \pm 0.18) \mathrm{ppb}$.

Although we are able to quantify the largest proportions which contribute to the bias between NDACC and TCCON data, we still identify a remaining bias of about $-0.35 \mathrm{ppb}$. Further differences might be induced by inconsistencies in spectroscopic parameters for MIR and NIR spectral ranges. Changes in HITRAN 2012 were mainly applied to the $\mathrm{CO}$ overtone absorption band in the NIR (e.g. line intensities, self- and air-broadening parameters, temperature dependence, and air-induced line shifts) while line intensities, temperature dependence, etc. remained unchanged in the MIR spectral domain. Furthermore, TCCON uses a customized HITRAN 2012 CO line list in the NIR, whereas we use the HITRAN 2008 line list in its original form for CO NDACC retrievals. Furthermore, we can rule out that the remaining bias is induced by the calculation of XCO. Our findings in Sect. 3.3 revealed that the total column of $\mathrm{O}_{2}$ retrieved from GGG2014 and PROFFIT is in good agreement and has negligible impact on the observed bias. The same holds for our findings in Sect. 3.5, which have shown that the impact of different spectroscopic parameters on the bias is not significant.

\subsection{Analysis of seasonality}

Our comparison shows a clear seasonal variation with a standard deviation of $2.06 \mathrm{ppb}$ in the difference time series (see
Fig. 9, upper panel). This seasonality is related to differing averaging kernels (AVKs) in the MIR and NIR, which are a function of pressure, slant column, and solar zenith angle and therefore variable with season. To estimate the smoothing effect in our comparison, we apply Eq. (4) for TCCON and NDACC AVKs assuming simulated model profiles as true atmospheric profiles. We retrieve NDACC and TCCON XCO using common a priori VMR profiles (daily TCCON a priori VMR profiles) to eliminate the effect of differing prior information (see Sect. 3.4). We expect to see a similar seasonality (with a comparable amplitude and phase) in the residual of the smoothed model data as in the original NDACC and TCCON XCO difference time series.

\subsubsection{Applying averaging kernels}

A smoothed profile $\boldsymbol{x}_{\mathrm{s}}$ can be computed when using e.g. a simulated VMR profile $\boldsymbol{x}_{\text {model }}$ as the true atmospheric profile. This leads to

$\boldsymbol{x}_{\mathrm{s}}=\mathbf{A}\left(\boldsymbol{x}_{\text {model }}-\boldsymbol{x}_{\text {apriori }}\right)+\boldsymbol{x}_{\text {apriori }}+\boldsymbol{\epsilon}$.

The difference $\Delta \boldsymbol{x}_{\mathrm{s}}$ between smoothed profiles using differing MIR and NIR AVKs is given by

$\Delta \boldsymbol{x}_{\mathrm{s}}=\left(\mathbf{A}_{\mathrm{MIR}-\mathrm{NIR}}\right)\left(\boldsymbol{x}_{\text {model }}-\boldsymbol{x}_{\text {apriori }}\right)$.

Here, $\mathbf{A}_{\text {MIR }}$ and $\mathbf{A}_{\text {NIR }}$ represent the differing NDACC and TCCON AVKs (see Figs. 10 and 11). Note, Eq. (6) only holds when we use a common a priori VMR profile and describes the impact from differing AVKs on the retrieved total columns when integrated over pressure layers, which is of major interest in our analysis.

\subsubsection{ECHAM/MESSy Atmospheric Chemistry (EMAC) model data}

We obtain the simulated CO profiles from the EMAC model. This is a numerical chemistry and climate simulation system that includes submodels describing tropospheric and middleatmospheric processes and their interaction with oceans, land, and human influences (Jöckel et al., 2006). It uses the second version of the Modular Earth Submodel System (MESSy2) to link multi-institutional computer codes (Jöckel et al., 2010). The core atmospheric model is the fifthgeneration European Centre Hamburg general circulation model (ECHAM5; Roeckner et al., 2006). For the present study we applied EMAC (ECHAM5 version 5.3.02, MESSy version 2.50) in the T42L39MA resolution, i.e. with a spherical truncation of T42 corresponding to approximately $2.8^{\circ}$ by $2.8^{\circ}$ in latitude and longitude with 39 vertical hybrid pressure levels up to $0.01 \mathrm{hPa}$ (approx. $80 \mathrm{~km}$ ) and with a time step of $10 \mathrm{~min}$. The approximate vertical resolution in the stratosphere is between 1.5 and $2.5 \mathrm{~km}$, decreasing with altitude. The simulation includes a comprehensive chemistry set-up from the troposphere to the lower mesosphere. Gasphase chemistry and heterogeneous reactions are calculated 


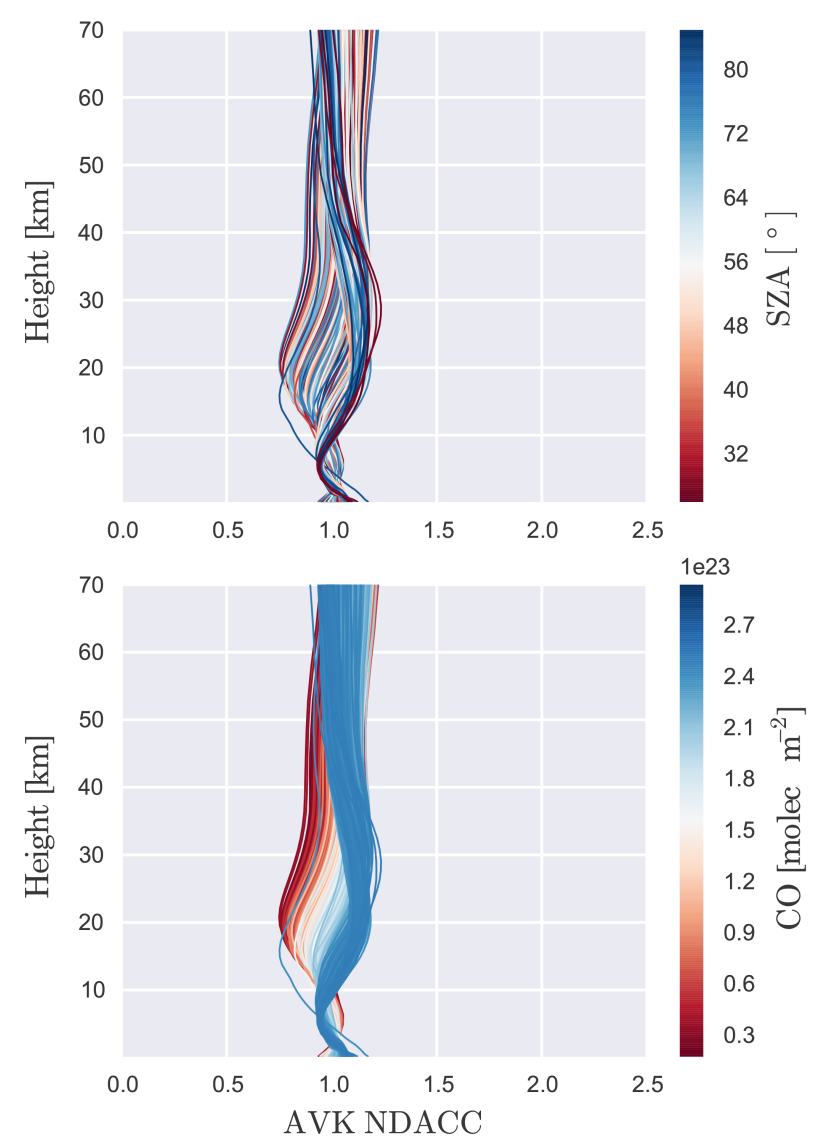

Figure 10. Column averaging kernels for the NDACC retrieval using MIR spectra. Different solar zenith angles (SZA) are colour coded (upper panel). For a better visualization, column averaging kernels are depicted for different CO slant columns (lower panel).

with the help of the submodels MECCA (Sander et al., 2005) and MSBM (Kirner et al., 2011). The gas-phase reaction rate coefficients for gas-phase reactions and absorption cross sections for photolysis are taken from Atkinson et al. (2007) and Sander et al. (2011). A Newtonian relaxation technique for the prognostic variables temperature, vorticity, divergence, and the surface pressure is implemented in EMAC to reproduce realistic synoptic conditions. We apply this nudging technique in our simulations above the boundary layer and below $1 \mathrm{hPa}$ using the ERA-Interim reanalysis (Dee et al., 2011) from the European Centre for Medium-range Weather Forecasts (ECMWF).

\subsubsection{Estimation of smoothing effect}

For our study, we apply NDACC and TCCON AVKs to one simulated CO profile (interpolated to the height levels used in our retrievals) per day at 12:00:00 UTC (see Fig. 12). Figure 13 (upper panel) shows calculated XCO when we apply Eq. (4) using differing AVKs and when we assume the simulated CO EMAC profiles as true atmospheric VMR profiles.

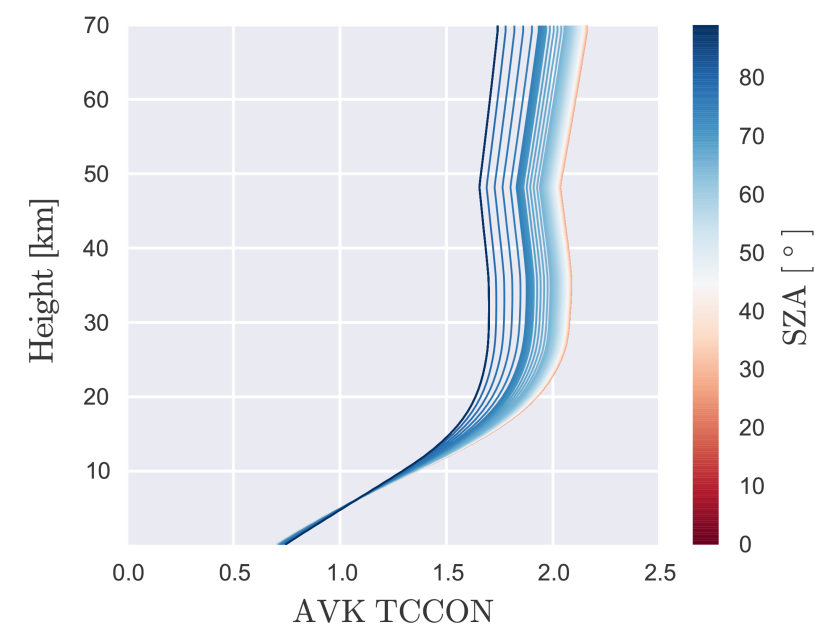

Figure 11. Column averaging kernels (mean of kernels from both NIR spectral windows) for the TCCON retrieval for different solar zenith angles (SZAs). Intermediate kernels are obtained from linearly interpolated averaging kernels from one Karlsruhe measurement day covering a wide range of SZA.

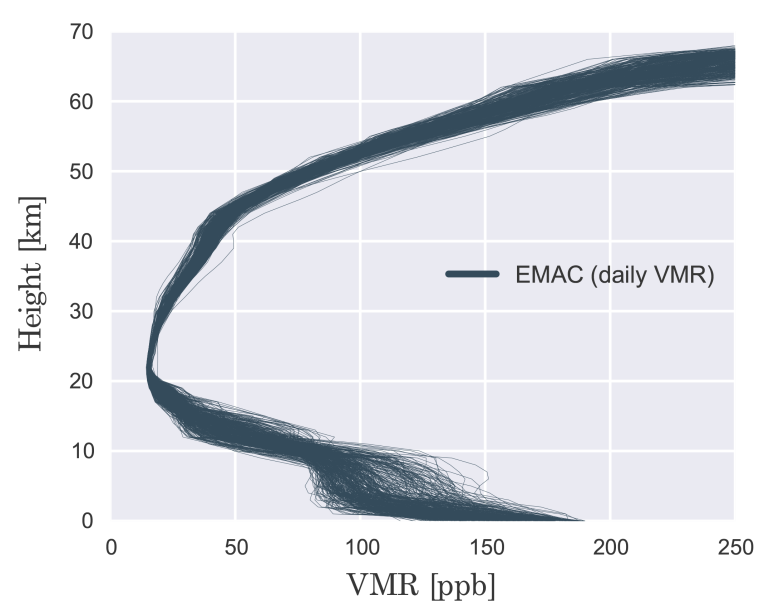

Figure 12. Simulated EMAC CO VMR profiles used in this study.

The residual (Fig. 13, lower panel) shows an oscillating behaviour with a standard deviation of $1.65 \mathrm{ppb}$ in seasonality. Our estimation shows that the smoothing effect induced due to differing AVKs is not negligible when comparing NDACC and TCCON XCO. The phase and amplitude of the oscillation is comparable to the seasonality of the originally retrieved difference between TCCON and NDACC XCO (see Fig. 13, lower panel). Therefore, the seasonal variation in the comparison of NDACC and TCCON XCO data can be largely explained by smoothing effects induced by differing AVKs from our retrievals in the MIR and NIR. For the potential joint use of XCO from NDACC and TCCON as a validating data set, it is important to note that $\triangle \mathrm{XCO}$ changes in sign with seasonality. Therefore, the impact of the smoothing effect from differing MIR and NIR AVKs has to be taken 


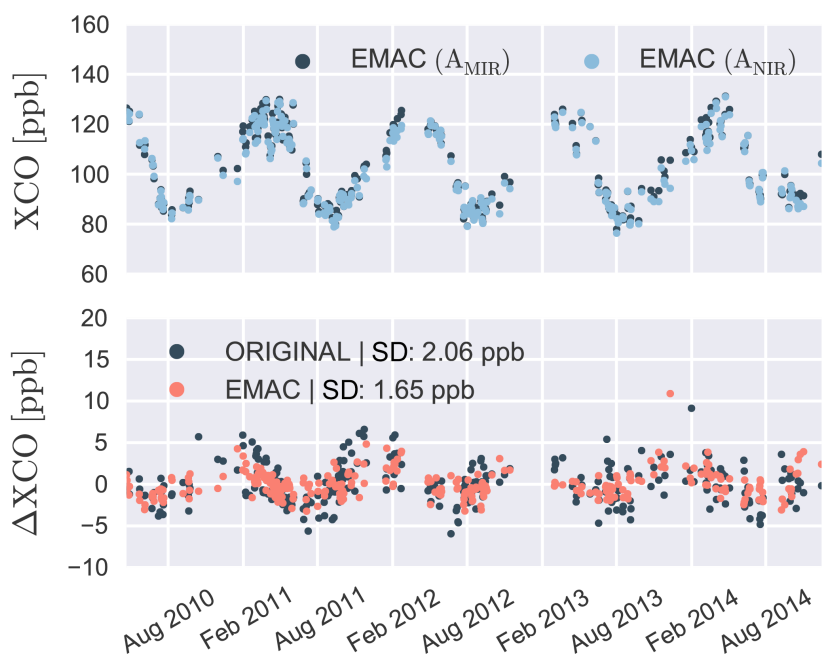

Figure 13. Smoothed XCO time series using NDACC and TCCON averaging kernels and simulated EMAC VMR profiles as the true atmospheric profile (upper panel); the lower panel shows the difference time series of both smoothed time series and is an estimate of the smoothing effect observed in the original time series, which represents the difference of the unmodified standard retrievals as used for NDACC and TCCON (labelled as "ORIGINAL"). For a better comparison of the seasonality, we removed the induced bias in both time series.

into account when using NDACC and TCCON XCO as a joint validation data set for different seasons.

\section{Conclusions}

In this work we compare Karlsruhe NDACC and TCCON XCO retrievals (April 2010-December 2014) from the fundamental absorption band $(4.7 \mu \mathrm{m})$ in the MIR and the first overtone absorption band $(2.3 \mu \mathrm{m})$ in the NIR. Karlsruhe is a good site for a direct comparison of NDACC and TCCON data records since the particular instrumental set-up allows to record spectra in the MIR and NIR simultaneously. We observe a bias of $(4.47 \pm 0.17)$ ppb between XCO retrieved from NDACC and TCCON using different retrieval algorithms and retrieval strategies. We identify and quantify different sources, which contribute to the observed bias. The air-mass-independent correction factor (1.0672) which is applied to TCCON XCO in the post-processing routine is the main source of the observed difference. The bias is reduced to $(-1.7 \pm 0.17) \mathrm{ppb}$ when this factor is not applied. Furthermore, the air-mass-dependent correction factor contributes $0.71 \mathrm{ppb}$ to the overall bias whereas a TCCON compatible treatment of different isotopic identities in the MIR retrieval strategy reduces the bias by $0.45 \mathrm{ppb}$. The impact of different a priori VMR profiles $(0.20 \mathrm{ppb})$ and the choice of different spectroscopic line lists $(0.05 \mathrm{ppb})$ has minor influence on the overall bias. A remaining bias of $(-0.35 \pm 0.18) \mathrm{ppb}$ might be subject to imperfect knowledge of the spectroscopic pa- rameters in the MIR and NIR. The impact due to differences in total columns of $\mathrm{O}_{2}$ for the calculation of DMFs is negligible with $(0.04 \pm 0.02) \mathrm{ppb}$. The seasonality in the residual of NDACC and TCCON XCO (standard deviation of $2.06 \mathrm{ppb}$ ) can be estimated by the smoothing effect caused by differing AVKs, which are a function of pressure, slant column, and SZA and vary with season. For the future use of XCO from NDACC and TCCON as a joint validation data set, it would be desirable to obtain an air-mass-independent correction factor for NDACC XCO retrievals from aircraft overflights to improve the comparability between both XCO time series. Until then, for a potential joint use of Karlsruhe XCO from TCCON and NDACC it might be favourable to tie the NDACC XCO time series to the WMO scale by dividing by 1.048 , a scaling factor obtained from the difference between Karlsruhe NDACC and TCCON XCO. 


\section{Appendix A: Additional Figures}
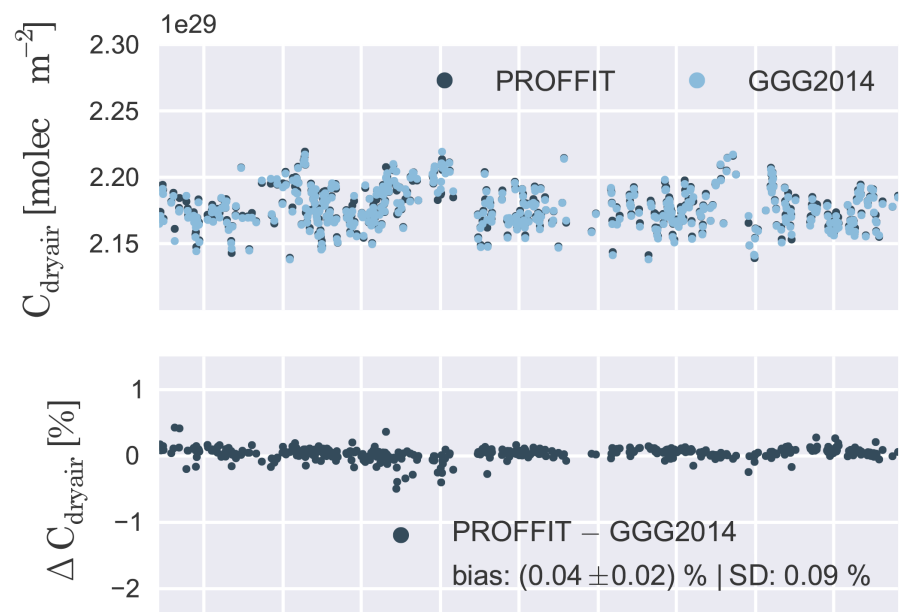

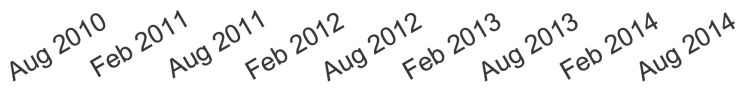

Figure A1. Upper panel: daily mean time series of $\mathrm{C}_{\text {dryair }}$ retrieved from the oxygen $7885 \mathrm{~cm}^{-1}$ absorption band using the PROFFIT and GGG2014 retrieval algorithm; lower panel: relative difference time series (PROFFIT - GGG2014). The impact of the bias and standard deviation in the seasonal cycle is rather small and only slightly affects XCO from MIR and NIR retrievals.

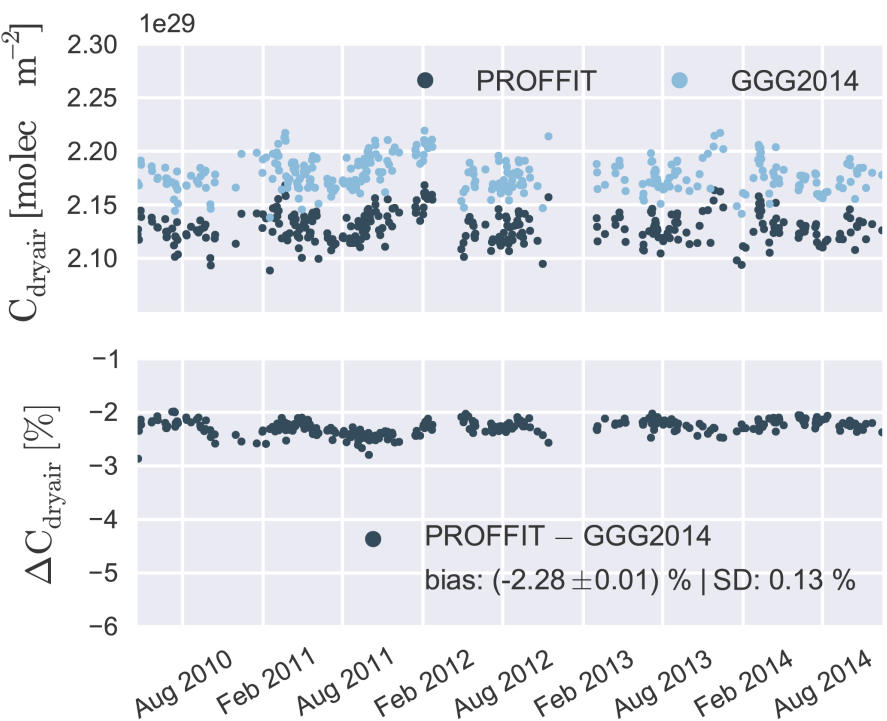

Figure A2. Retrieved total columns of dry air using Eq. (2) (GGG2014) and Eq. (3) (PROFFIT) are shown in the upper panel. The lower panel shows the relative difference. 

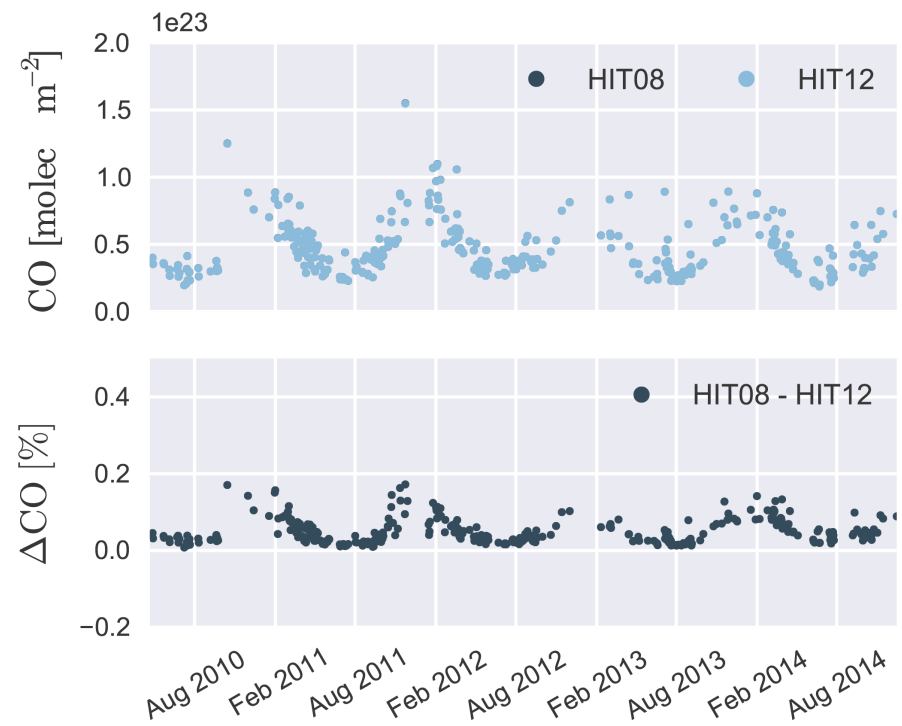

Figure A3. Upper panel: daily mean time series of CO slant columns retrieved from MIR spectra for HITRAN 2008 (HIT08) and HITRAN 2012 (HIT12); the lower panel shows the relative difference time series. The maxima in both time series are in phase.

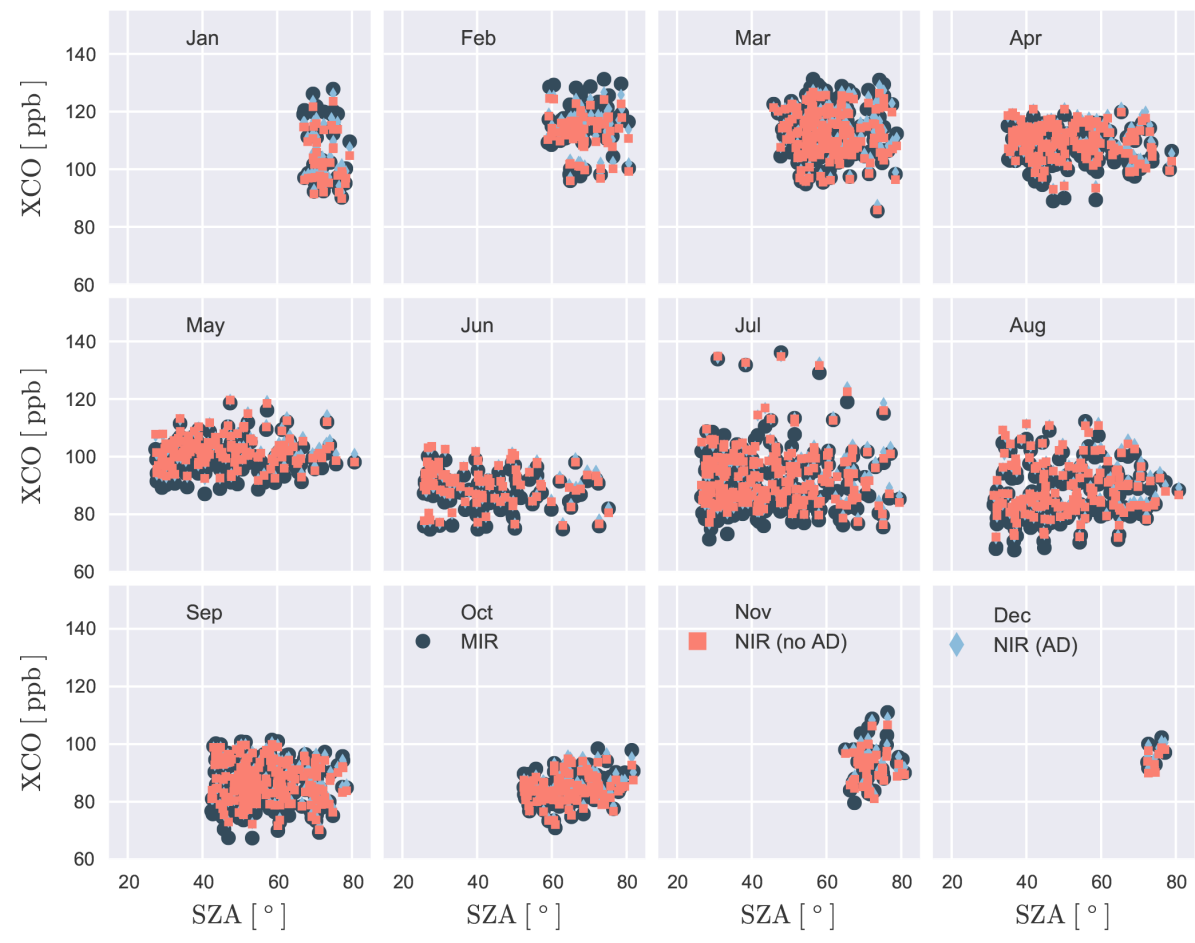

Figure A4. Air-mass-dependence of XCO split in months for NDACC (MIR) and TCCON with (AD) and without air-mass-dependent correction factor (no AD). 

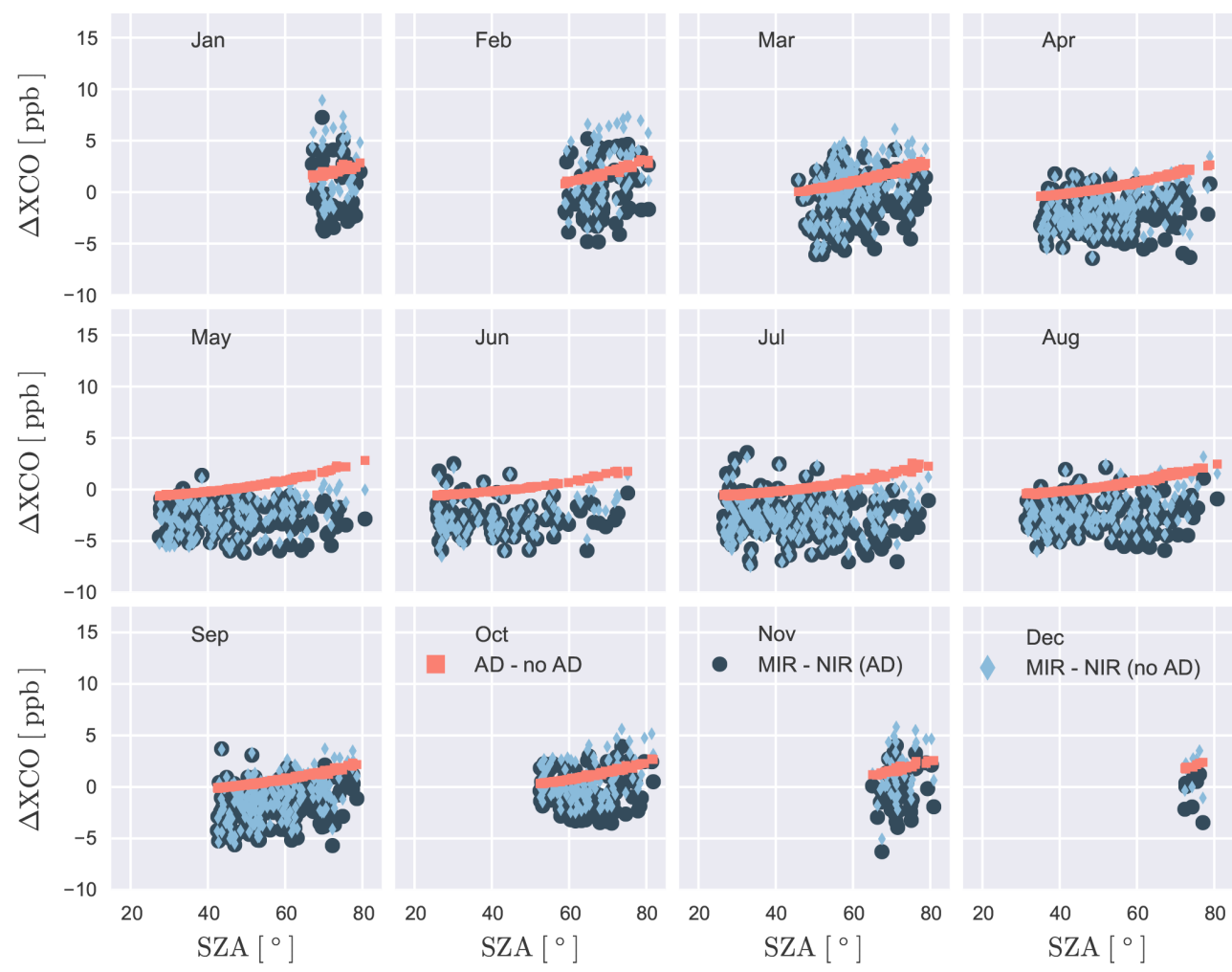

Figure A5. Air-mass-dependent XCO differences between NDACC and TCCON. Depicted are absolute differences between NDACC and TCCON when AD is applied (MIR-NIR AD), NDACC and TCCON when no AD is applied (MIR-NIR no AD), and the direct impact of applying $\mathrm{AD}$ in the TCCON retrieval (AD-no $\mathrm{AD}$ ). 
Acknowledgements. The research leading to these results has received funding from the European Community's Seventh Framework Programme (FP7/2007-2013) under grant agreement no. 284421 (NORS project). We thank Debra Wunch, Paul O. Wennberg (both California Institute of Technology, Pasadena), and Geoffrey C. Toon (Jet Propulsion Laboratory, Pasadena) for their helpful comments. We acknowledge Martin Kohler from the Institute for Meteorology and Climate Research - Troposphere Research (IMK-TRO) at the KIT for providing tall-tower meteorological data. We acknowledge support by Deutsche Forschungsgemeinschaft and Open Access Publishing Fund of the Karlsruhe Institute of Technology.

The article processing charges for this open-access

publication were covered by a Research

Centre of the Helmholtz Association.

Edited by: H. Maring

\section{References}

Atkinson, R., Baulch, D. L., Cox, R. A., Crowley, J. N., Hampson, R. F., Hynes, R. G., Jenkin, M. E., Rossi, M. J., and Troe, J.: Evaluated kinetic and photochemical data for atmospheric chemistry: Volume III - gas phase reactions of inorganic halogens, Atmos. Chem. Phys., 7, 981-1191, doi:10.5194/acp-7-981-2007, 2007.

Borsdorff, T., Tol, P., Williams, J. E., de Laat, J., aan de Brugh, J., Nédélec, P., Aben, I., and Landgraf, J.: Carbon monoxide total columns from SCIAMACHY $2.3 \mu \mathrm{m}$ atmospheric reflectance measurements: towards a full-mission data product (2003-2012), Atmos. Meas. Tech., 9, 227-248, doi:10.5194/amt-9-227-2016, 2016.

Bovensmann, H., Burrows, J. P., Buchwitz, M., Frerick, J., Noël, S., Rozanov, V. V., Chance, K. V., and Goede, A. P. H.: SCIAMACHY: Mission Objectives and Measurement Modes, J. Atmos. Sci., 56, 127-150, doi:10.1175/15200469(1999)056<0127:SMOAMM>2.0.CO;2, 1999.

Buchwitz, M., Khlystova, I., Bovensmann, H., and Burrows, J. P.: Three years of global carbon monoxide from SCIAMACHY: comparison with MOPITT and first results related to the detection of enhanced CO over cities, Atmos. Chem. Phys., 7, 23992411, doi:10.5194/acp-7-2399-2007, 2007.

Clerbaux, C., George, M., Turquety, S., Walker, K. A., Barret, B., Bernath, P., Boone, C., Borsdorff, T., Cammas, J. P., Catoire, V., Coffey, M., Coheur, P.-F., Deeter, M., De Mazière, M., Drummond, J., Duchatelet, P., Dupuy, E., de Zafra, R., Eddounia, F., Edwards, D. P., Emmons, L., Funke, B., Gille, J., Griffith, D. W. T., Hannigan, J., Hase, F., Höpfner, M., Jones, N., Kagawa, A., Kasai, Y., Kramer, I., Le Flochmoën, E., Livesey, N. J., López-Puertas, M., Luo, M., Mahieu, E., Murtagh, D., Nédélec, P., Pazmino, A., Pumphrey, H., Ricaud, P., Rinsland, C. P., Robert, C., Schneider, M., Senten, C., Stiller, G., Strandberg, A., Strong, K., Sussmann, R., Thouret, V., Urban, J., and Wiacek, A.: CO measurements from the ACE-FTS satellite instrument: data analysis and validation using ground-based, airborne and spaceborne observations, Atmos. Chem. Phys., 8, 2569-2594, doi:10.5194/acp-8-2569-2008, 2008.
Daniel, J. S. and Solomon, S.: On the climate forcing of carbon monoxide, J. Geophys. Res.-Atmos., 103, 13249-13260, doi:10.1029/98JD00822, 1998.

De Biévre, P., Gallet, M., Holden, N. E., and Barnes, I. L.: Isotopic Abundances and Atomic Weights of the Elements, J. Phys. Chem. Ref. Data, 13, 809-891, doi:10.1063/1.555720, 1984.

de Laat, A. T. J., Gloudemans, A. M. S., Schrijver, H., Aben, I., Nagahama, Y., Suzuki, K., Mahieu, E., Jones, N. B., Paton-Walsh, C., Deutscher, N. M., Griffith, D. W. T., De Mazière, M., Mittermeier, R. L., Fast, H., Notholt, J., Palm, M., Hawat, T., Blumenstock, T., Hase, F., Schneider, M., Rinsland, C., Dzhola, A. V., Grechko, E. I., Poberovskii, A. M., Makarova, M. V., Mellqvist, J., Strandberg, A., Sussmann, R., Borsdorff, T., and Rettinger, M.: Validation of five years (2003-2007) of SCIAMACHY CO total column measurements using ground-based spectrometer observations, Atmos. Meas. Tech., 3, 1457-1471, doi:10.5194/amt3-1457-2010, 2010.

Dee, D. P., Uppala, S. M., Simmons, A. J., Berrisford, P., Poli, P., Kobayashi, S., Andrae, U., Balmaseda, M. A., Balsamo, G., Bauer, P., Bechtold, P., Beljaars, A. C. M., van de Berg, L., Bidlot, J., Bormann, N., Delsol, C., Dragani, R., Fuentes, M., Geer, A. J., Haimberger, L., Healy, S. B., Hersbach, H., Hólm, E. V., Isaksen, L., Kållberg, P., Köhler, M., Matricardi, M., McNally, A. P., Monge-Sanz, B. M., Morcrette, J.-J., Park, B.-K., Peubey, C., de Rosnay, P., Tavolato, C., Thépaut, J.-N., and Vitart, F.: The ERA-Interim reanalysis: configuration and performance of the data assimilation system, Q. J. Roy. Meteor. Soc., 137, 553-597, doi:10.1002/qj.828, 2011.

Deeter, M. N., Emmons, L. K., Francis, G. L., Edwards, D. P., Gille, J. C., Warner, J. X., Khattatov, B., Ziskin, D., Lamarque, J.-F., Ho, S.-P., Yudin, V., Attié, J.-L., Packman, D., Chen, J., Mao, D., and Drummond, J. R.: Operational carbon monoxide retrieval algorithm and selected results for the MOPITT instrument, J. Geophys. Res.-Atmos., 108, 4399, doi:10.1029/2002JD003186, 2003.

Deutscher, N. M., Griffith, D. W. T., Bryant, G. W., Wennberg, P. O., Toon, G. C., Washenfelder, R. A., Keppel-Aleks, G., Wunch, D., Yavin, Y., Allen, N. T., Blavier, J.-F., Jiménez, R., Daube, B. C., Bright, A. V., Matross, D. M., Wofsy, S. C., and Park, S.: Total column $\mathrm{CO}_{2}$ measurements at Darwin, Australia - site description and calibration against in situ aircraft profiles, Atmos. Meas. Tech., 3, 947-958, doi:10.5194/amt-3-947-2010, 2010.

Frey, M., Hase, F., Blumenstock, T., Groß, J., Kiel, M., Mengistu Tsidu, G., Schäfer, K., Sha, M. K., and Orphal, J.: Calibration and instrumental line shape characterization of a set of portable FTIR spectrometers for detecting greenhouse gas emissions, Atmos. Meas. Tech., 8, 3047-3057, doi:10.5194/amt-8-3047-2015, 2015.

Garcia, R. R., Marsh, D. R., Kinnison, D. E., Boville, B. A., and Sassi, F.: Simulation of secular trends in the middle atmosphere, 1950-2003, J. Geophys. Res.-Atmos., 112, doi:10.1029/2006JD007485, d09301, 2007.

Geibel, M. C., Messerschmidt, J., Gerbig, C., Blumenstock, T., Chen, H., Hase, F., Kolle, O., Lavric, J. V., Notholt, J., Palm, M., Rettinger, M., Schmidt, M., Sussmann, R., Warneke, T., and Feist, D. G.: Calibration of column-averaged $\mathrm{CH}_{4}$ over European TCCON FTS sites with airborne in-situ measurements, Atmos. Chem. Phys., 12, 8763-8775, doi:10.5194/acp-12-87632012, 2012. 
Gisi, M., Hase, F., Dohe, S., Blumenstock, T., Simon, A., and Keens, A.: $\mathrm{XCO}_{2}$-measurements with a tabletop FTS using solar absorption spectroscopy, Atmos. Meas. Tech., 5, 2969-2980, doi:10.5194/amt-5-2969-2012, 2012.

Hase, F., Hannigan, J., Coffey, M., Goldman, A., Höpfner, M., Jones, N., Rinsland, C., and Wood, S.: Intercomparison of retrieval codes used for the analysis of high-resolution, groundbased FTIR measurements, J. Quant. Spectrosc. Ra., 87, 25-52, doi:10.1016/j.jqsrt.2003.12.008, 2004.

Hase, F., Frey, M., Blumenstock, T., Groß, J., Kiel, M., Kohlhepp, R., Mengistu Tsidu, G., Schäfer, K., Sha, M. K., and Orphal, J.: Application of portable FTIR spectrometers for detecting greenhouse gas emissions of the major city Berlin, Atmos. Meas. Tech., 8, 3059-3068, doi:10.5194/amt-8-3059-2015, 2015.

Jöckel, P., Tost, H., Pozzer, A., Brühl, C., Buchholz, J., Ganzeveld, L., Hoor, P., Kerkweg, A., Lawrence, M. G., Sander, R., Steil, B., Stiller, G., Tanarhte, M., Taraborrelli, D., van Aardenne, J., and Lelieveld, J.: The atmospheric chemistry general circulation model ECHAM5/MESSy1: consistent simulation of ozone from the surface to the mesosphere, Atmos. Chem. Phys., 6, 50675104, doi:10.5194/acp-6-5067-2006, 2006.

Jöckel, P., Kerkweg, A., Pozzer, A., Sander, R., Tost, H., Riede, H., Baumgaertner, A., Gromov, S., and Kern, B.: Development cycle 2 of the Modular Earth Submodel System (MESSy2), Geosci. Model Dev., 3, 717-752, doi:10.5194/gmd-3-717-2010, 2010.

Karion, A., Sweeney, C., Tans, P., and Newberger, T.: AirCore: An Innovative Atmospheric Sampling System, J. Atmos. Ocean. Tech., 27, 1839-1853, doi:10.1175/2010JTECHA1448.1, 2010.

Kiel, M., Wunch, D., Wennberg, P. O., Toon, G. C., Hase, F., and Blumenstock, T.: Improved retrieval of gas abundances from near-infrared solar FTIR spectra measured at the Karlsruhe TCCON station, Atmos. Meas. Tech., 9, 669-682, doi:10.5194/amt9-669-2016, 2016.

Kirner, O., Ruhnke, R., Buchholz-Dietsch, J., Jöckel, P., Brühl, C., and Steil, B.: Simulation of polar stratospheric clouds in the chemistry-climate-model EMAC via the submodel PSC, Geosci. Model Dev., 4, 169-182, doi:10.5194/gmd-4-169-2011, 2011.

Klappenbach, F., Bertleff, M., Kostinek, J., Hase, F., Blumenstock, T., Agusti-Panareda, A., Razinger, M., and Butz, A.: Accurate mobile remote sensing of $\mathrm{XCO}_{2}$ and $\mathrm{XCH}_{4}$ latitudinal transects from aboard a research vessel, Atmos. Meas. Tech., 8, 50235038, doi:10.5194/amt-8-5023-2015, 2015.

Kramer, I.: Time series of tropospheric trace gases derived from ground-based FTIR measurements, PhD thesis, Karlsruhe Institute of Technology, 2007.

Kurylo, M. J.: Network for the detection of stratospheric change, Proc. SPIE, 1491, 168-174, doi:10.1117/12.46658, 1991.

Messerschmidt, J., Geibel, M. C., Blumenstock, T., Chen, H., Deutscher, N. M., Engel, A., Feist, D. G., Gerbig, C., Gisi, M., Hase, F., Katrynski, K., Kolle, O., Lavric, J. V., Notholt, J., Palm, M., Ramonet, M., Rettinger, M., Schmidt, M., Sussmann, R., Toon, G. C., Truong, F., Warneke, T., Wennberg, P. O., Wunch, D., and Xueref-Remy, I.: Calibration of TCCON column-averaged $\mathrm{CO}_{2}$ : the first aircraft campaign over European TCCON sites, Atmos. Chem. Phys., 11, 10765-10777, doi:10.5194/acp-11-10765-2011, 2011.

Rienecker, M. M., Suarez, M. J., Gelaro, R., Todling, R., Bacmeister, J., Liu, E., Bosilovich, M. G., Schubert, S. D., Takacs, L., Kim, G.-K., Bloom, S., Chen, J., Collins, D., Conaty, A., da Silva, A., Gu, W., Joiner, J., Koster, R. D., Lucchesi, R., Molod, A., Owens, T., Pawson, S., Pegion, P., Redder, C. R., Reichle, R., Robertson, F. R., Ruddick, A. G., Sienkiewicz, M., and Woollen, J.: MERRA: NASA's Modern-Era Retrospective Analysis for Research and Applications, J. Climate, 24, 3624-3648, doi:10.1175/JCLI-D-11-00015.1, 2011.

Rodgers, C. D. and Connor, B. J.: Intercomparison of remote sounding instruments, J. Geophys. Res.-Atmos., 108, 4116-4229, doi:10.1029/2002JD002299, 2003.

Roeckner, E., Brokopf, R., Esch, M., Giorgetta, M., Hagemann, S., Kornblueh, L., Manzini, E., Schlese, U., and Schulzweida, U.: Sensitivity of Simulated Climate to Horizontal and Vertical Resolution in the ECHAM5 Atmosphere Model, J. Climate, 19, 3771-3791, doi:10.1175/JCLI3824.1, 2006.

Rothman, L., Gordon, I., Barbe, A., Benner, D., Bernath, P., Birk, M., Boudon, V., Brown, L., Campargue, A., Champion, J.-P., Chance, K., Coudert, L., Dana, V., Devi, V., Fally, S., Flaud, J.M., Gamache, R., Goldman, A., Jacquemart, D., Kleiner, I., Lacome, N., Lafferty, W., Mandin, J.-Y., Massie, S., Mikhailenko, S., Miller, C., Moazzen-Ahmadi, N., Naumenko, O., Nikitin, A., Orphal, J., Perevalov, V., Perrin, A., Predoi-Cross, A., Rinsland, C., Rotger, M., Šimečková, M., Smith, M., Sung, K., Tashkun, S., Tennyson, J., Toth, R., Vandaele, A., and Auwera, J. V.: The HITRAN 2008 molecular spectroscopic database, J. Quant. Spectrosc. Ra., 110, 533-572, doi:10.1016/j.jqsrt.2009.02.013, hITRAN, 2009.

Rothman, L., Gordon, I., Babikov, Y., Barbe, A., Benner, D. C., Bernath, P., Birk, M., Bizzocchi, L., Boudon, V., Brown, L., Campargue, A., Chance, K., Cohen, E., Coudert, L., Devi, V., Drouin, B., Fayt, A., Flaud, J.-M., Gamache, R., Harrison, J., Hartmann, J.-M., Hill, C., Hodges, J., Jacquemart, D., Jolly, A., Lamouroux, J., Roy, R. L., Li, G., Long, D., Lyulin, O., Mackie, C., Massie, S., Mikhailenko, S., Müller, H., Naumenko, O., Nikitin, A., Orphal, J., Perevalov, V., Perrin, A., Polovtseva, E., Richard, C., Smith, M., Starikova, E., Sung, K., Tashkun, S., Tennyson, J., Toon, G., Tyuterev, V., and Wagner, G.: The HITRAN2012 molecular spectroscopic database, J. Quant. Spectrosc. Ra., 130, 4-50, doi:10.1016/j.jqsrt.2013.07.002, 2013.

Sander, R., Kerkweg, A., Jöckel, P., and Lelieveld, J.: Technical note: The new comprehensive atmospheric chemistry module MECCA, Atmos. Chem. Phys., 5, 445-450, doi:10.5194/acp-5445-2005, 2005.

Sander, S., Friedl, R., Barker, J., Golden, D., Rylo, M., Wine, P., Abbatt, J., Burkholder, J., Kolb, C. E., d Moortgat, G., Huie, R., and Orkin, V.: Chemical kinetics and photochemical data for use in atmospheric sudies: Evaluation No. 17, JPL Publication 10-6, Jet Propulsion Laboratory, Pasadena, USA, 2011.

Schneider, M., Hase, F., and Blumenstock, T.: Water vapour profiles by ground-based FTIR spectroscopy: study for an optimised retrieval and its validation, Atmos. Chem. Phys., 6, 811-830, doi:10.5194/acp-6-811-2006, 2006.

Seiler, W. and Fishman, J.: The distribution of carbon monoxide and ozone in the free troposphere, J. Geophys. Res.-Oceans, 86, 7255-7265, doi:10.1029/JC086iC08p07255, 1981.

Spivakovsky, C., Logan, J., Montzka, S., Balkanski, Y., ForemanFowler, M., Jones, D., Horowitz, L., Fusco, A., Brenninkmeijer, C., Prather, M., Wofsy, S. C., and McElroy, M. B.: Threedimensional climatological distribution of tropospheric $\mathrm{OH}$ : 
Update and evaluation, J. Geophys. Res., 105, 8931-8980, doi:10.1029/1999JD901006, 2000.

Sussmann, R., Stremme, W., Buchwitz, M., and de Beek, R.: Validation of ENVISAT/SCIAMACHY columnar methane by solar FTIR spectrometry at the Ground-Truthing Station Zugspitze, Atmos. Chem. Phys., 5, 2419-2429, doi:10.5194/acp-5-24192005, 2005.

Sussmann, R., Forster, F., Rettinger, M., and Jones, N.: Strategy for high-accuracy-and-precision retrieval of atmospheric methane from the mid-infrared FTIR network, Atmos. Meas. Tech., 4, 1943-1964, doi:10.5194/amt-4-1943-2011, 2011.

Toon, G. C.: The JPL MkIV interferometer, Opt. Photon. News, 2, 19-21, doi:10.1364/OPN.2.10.000019, 1991.

Vidot, J., Landgraf, J., Hasekamp, O., Butz, A., Galli, A., Tol, P., and Aben, I.: Carbon monoxide from shortwave infrared reflectance measurements: A new retrieval approach for clear sky and partially cloudy atmospheres, Remote Sens. Environ., 120, 255-266, doi:10.1016/j.rse.2011.09.032, 2012.

Wang, Z., Chappellaz, J., Martinerie, P., Park, K., Petrenko, V., Witrant, E., Emmons, L. K., Blunier, T., Brenninkmeijer, C. A. M., and Mak, J. E.: The isotopic record of Northern Hemisphere atmospheric carbon monoxide since 1950: implications for the CO budget, Atmos. Chem. Phys., 12, 4365-4377, doi:10.5194/acp-12-4365-2012, 2012.

Washenfelder, R. A., Toon, G. C., Blavier, J.-F., Yang, Z., Allen, N. T., Wennberg, P. O., Vay, S. A., Matross, D. M., and Daube, B. C.: Carbon dioxide column abundances at the Wisconsin Tall Tower site, J. Geophys. Res.-Atmos., 111, D22305, doi:10.1029/2006JD007154, 2006.
Wofsy, S. C.: HIAPER Pole-to-Pole Observations (HIPPO): finegrained, global-scale measurements of climatically important atmospheric gases and aerosols, Philos. T. Roy. Soc. A, 369, 2073 2086, doi:10.1098/rsta.2010.0313, 2011.

Wunch, D., Toon, G. C., Wennberg, P. O., Wofsy, S. C., Stephens, B. B., Fischer, M. L., Uchino, O., Abshire, J. B., Bernath, P., Biraud, S. C., Blavier, J.-F. L., Boone, C., Bowman, K. P., Browell, E. V., Campos, T., Connor, B. J., Daube, B. C., Deutscher, N. M., Diao, M., Elkins, J. W., Gerbig, C., Gottlieb, E., Griffith, D. W. T., Hurst, D. F., Jiménez, R., Keppel-Aleks, G., Kort, E. A., Macatangay, R., Machida, T., Matsueda, H., Moore, F., Morino, I., Park, S., Robinson, J., Roehl, C. M., Sawa, Y., Sherlock, V., Sweeney, C., Tanaka, T., and Zondlo, M. A.: Calibration of the Total Carbon Column Observing Network using aircraft profile data, Atmos. Meas. Tech., 3, 1351-1362, doi:10.5194/amt3-1351-2010, 2010.

Wunch, D., Toon, G. C., Blavier, J.-F. L., Washenfelder, R. A., Notholt, J., Connor, B. J., Griffith, D. W. T., Sherlock, V., and Wennberg, P. O.: The Total Carbon Column Observing Network, Philos. T. Roy. Soc. A, 369, 2087-2112, doi:10.1098/rsta.2010.0240, 2011.

Wunch, D., Toon, G. C., Sherlock, V., Deutscher, N. M., Liu, C., Feist, D. G., and Wennberg, P. O.: The Total Carbon Column Observing Network's GGG2014 Data Version, Tech. rep., Carbon Dioxide Information Analysis Center, Oak Ridge National Laboratory, Oak Ridge, Tennessee, USA, doi:10.14291/tccon.ggg2014.documentation.R0/1221662, 2015. 